\title{
LncRNA Mrhl orchestrates differentiation programs in mouse embryonic stem cells
}

\section{through chromatin mediated regulation}

Debosree Pal ${ }^{1}$, Neha C V ${ }^{1,2}$, Utsa Bhaduri ${ }^{1}$, Zenia ${ }^{1}$, Subbulakshmi Chidambaram ${ }^{3}$, M.R.S Rao ${ }^{1, \#}$

1 Molecular Biology and Genetics Unit, Jawaharlal Nehru Centre for Advanced Scientific

7 Research, Jakkur P. O., Bangalore 560064

82 Present address: Department of Cell and Developmental Biology, University of Illinois at 9 Urbana-Champaign, Urbana, IL 61801, USA

103 Department of Biochemistry and Molecular Biology, Pondicherry University, Puducherry$11 \quad 605014$

12 \# Address of correspondence to: Prof. M.R.S.Rao at Molecular Biology and Genetics Unit,

13 Jawaharlal Nehru Centre for Advanced Scientific Research, Jakkur P. O., Bangalore 560064,

14 India. Tel.: 91-80-2208-2864; Fax: 91-80-2362-2762; E-mail: mrsrao@ jncasr.ac.in

\section{Abstract}

17 Long non-coding RNAs (lncRNAs) have been well-established to act as regulators and mediators

18 of development and cell fate specification programs. LncRNA Mrhl (meiotic recombination

19 hotspot locus) has been shown to act in a negative feedback loop with WNT signaling to regulate

20 male germ cell meiotic commitment. In our current study, we have addressed the role of Mrhl in

21 development and differentiation using mouse embryonic stem cells (mESCs) as our model

22 system of study. We found Mrhl to be a nuclear-localized, chromatin-bound lncRNA with

23 moderately stable expression in mESCs. Transcriptome analyses and loss-of-function phenotype

24 studies revealed dysregulation of developmental processes and lineage-specific genes along with

25 aberrance in specification of early lineages during differentiation of mESCs. Genome-wide 26 chromatin occupancy studies suggest regulation of chromatin architecture at key target loci 27 through triplex formation. Our studies thus reveal a role for lncRNA Mrhl in regulating 28 differentiation programs in mESCs in the context of appropriate cues through chromatin29 mediated responses.

\section{Keywords}

31 Mrhl, LncRNA, Embryonic stem cells, Transcriptome, Chromatin, Differentiation, Development 


\section{Introduction}

33 Since their discovery, embryonic stem cells (ESCs) and their potential in regenerative medicine

34 have been widely established. They have been programmed to form cone cells for the treatment

35 of age-related macular degeneration (Zhou et al., 2015), used for the treatment of spinal cord

36 injury patients (Shroff \& Gupta, 2015), differentiated into cardiomyocytes for cardiac tissue

37 injury repair (Shiba et al., 2012) or into insulin secreting $\beta$-cells for treating Type II diabetes

38 (Bruin et al., 2015; Salguero-Aranda et al., 2016). Their self-renewal characteristics coupled with

39 their capacity to differentiate into cell types of origin pertaining to all the three germ layers make

40 them an attractive model system to study queries related to development (Evans \& Kaufman,

41 1981; Martin, 1981). This entails that the molecular pathways and players contributing to the

42 physiology of stem cells be thoroughly characterized to explore their therapeutic potential to the

43 fullest.

45 Long non-coding RNAs (lncRNAs) have been classified as non-coding RNAs that are >200nt in 46 length and have been well-established to regulate diverse physiological phenomena from 47 development to disease. Although they are similar to mRNAs in aspects such as transcription by 48 RNA Pol II, 5' capping, 3' polyadenylation, splicing and possession of histone modification 49 signatures of active transcription across their promoters and gene bodies (Guttman et al., 2009), 50 they differ in other aspects such as low abundance, high tissue-specificity, lower stability and 51 lesser evolutionary conservation (Ard, Allshire, \& Marquardt, 2017; Mercer, Dinger, \& Mattick, 52 2009). Furthermore, they can be localized either in the nucleus or in the cytoplasm to perform 53 their diverse regulatory functions such as regulation of chromatin architecture (Rinn et al., 2007; 54 Zhao, Sun, Erwin, Song, \& Lee, 2008), genomic imprinting (Pandey et al., 2008; Ripoche, Kress, 55 Poirier, \& Dandolo, 1997; Sleutels, Zwart, \& Barlow, 2002), competitive endogenous RNAs 56 (Cesana et al., 2011; Lu et al., 2016), natural antisense transcripts (Faghihi et al., 2008; Ohhata, 57 Hoki, Sasaki, \& Sado, 2008), Staufen-mediated mRNA decay or modulation of protein activity 58 (Arun, Akhade, Donakonda, \& Rao, 2012; N. Lin et al., 2014; Marchese et al., 2016). LncRNAs 59 are being increasingly understood in terms of regulation of the nuclear architecture through the

60 formation of speckles and paraspeckles and tethering of distal chromosomes (Caudron-Herger et 61 al., 2015; Caudron-Herger \& Rippe, 2012; Hacisuleyman et al., 2014; Jacob, Audas, Uniacke, 
Trinkle-Mulcahy, \& Lee, 2013; Shevtsov \& Dundr, 2011; Souquere, Beauclair, Harper, Fox, \&

63 Pierron, 2010).

64 In embryonic stem cells (ESCs), genome-wide studies and functional analysis of individual

65 IncRNAs have shown them to participate in maintaining pluripotency (Bergmann et al., 2015;

66 Guttman et al., 2011; Sheik Mohamed, Gaughwin, Lim, Robson, \& Lipovich, 2010; Z. Sun et al.,

67 2018; Tu, Tian, Cheung, Wei, \& Lee, 2018) as well as in orchestrating differentiation and cell

68 fate specification programs (Flynn \& Chang, 2014; Klattenhoff et al., 2013; Ulitsky,

69 Shkumatava, Jan, Sive, \& Bartel, 2011), in association with transcription factors, chromatin

70 modifiers and RNA binding proteins. Interestingly, a few of these lncRNAs perform multiple

71 roles as a function of the cellular contexts and interaction partners. LncRNA Gomafu/Miat/Rncr2

72 is involved in maintaining pluripotency of mouse ESCs (mESCs) (Sheik Mohamed et al., 2010),

73 specification of the oligodendrocyte lineage in neural stem cells (Mercer et al., 2010) and

74 osteogenic lineage differentiation in adipose-derived stem cells (Jin et al., 2017). LncRNA Tuna

75 has been implicated in maintaining pluripotency of mESCs as well as their differentiation into

76 the neural lineage through forming a complex with PTBP1, hnRNP-K and NCL that occupies

77 promoters of Nanog, Sox2 and Fgf4 (N. Lin et al., 2014). LncRNA Tsx has also been shown to

78 be involved in the maintenance of mESCs, pachytene spermatocytes in testes and regulation of

79 cognition and behaviour in mice (Anguera et al., 2011). These examples suggest the diversity

80 and the context-dependant regulatory functions of lncRNAs in stem cell physiology and demand

81 further investigations on the roles of lncRNAs in ESCs.

83 LncRNA Mrhl (meiotic recombination hotspot locus) was discovered in our laboratory and has

84 been extensively studied in the context of male germ cell meiotic commitment. It is a $2.4 \mathrm{~kb}$

85 long, sense, intronic and single-exonic lncRNA, encoded within the 15th intron of the Phkb gene

86 in mouse (Nishant, Ravishankar, \& Rao, 2004) and is syntenically conserved in humans (Fatima,

87 Choudhury, Divya, Bhaduri, \& Rao, 2018). It has been shown to act in a negative feedback loop

88 with WNT signaling in association with its interaction partner p68 to regulate meiotic

89 progression of type B spermatogonial cells (Akhade, Dighe, Kataruka, \& Rao, 2016; Arun et al.,

90 2012). Genome-wide chromatin occupancy studies have revealed regulation of key genes

91 involved in spermatogenesis and WNT signaling by Mrhl in a p68 dependant manner, one of

92 them being the transcription factor SOX8 (Akhade, Arun, Donakonda, \& Rao, 2014). 
93 Subsequent studies have delineated the mechanisms of WNT mediated down regulation of Mrhl

94 through the recruitment of the co-repressor CTBP1 at the promoter of Mrhl and regulation of

95 SOX8 by Mrhl through MYC-MAD-MAX complexes (Kataruka, Akhade, Kayyar, \& Rao,

96 2017), suggesting an intricate network of Mrhl and associated proteins acting to orchestrate the

97 process of male germ cell meiosis.

In purview of the aforesaid, we have addressed the role of lncRNA Mrhl in mESCs to understand

100 it as a molecular player in development and differentiation. We demonstrate through

101 transcriptome studies that depletion of Mrhl in mESCs leads to dysregulation of 1143 genes with

102 major perturbation of developmental processes and genes including lineage-specific transcription

103 factors (TFs) and cell adhesion and receptor activity related genes. mESCs with stable

104 knockdown of Mrhl displayed aberrance in specification of ectoderm and mesoderm lineages

105 with no changes in the pluripotency status of the cells, consistent with our transcriptome data.

106 Genome-wide chromatin occupancy studies showed Mrhl to be associated with 22,000 loci. To

107 decipher chromatin-mediated target gene regulation, we overlapped the two datasets and found

108 key developmental TFs such as RUNX2, POU3F2 and FOXP2 to be directly regulated by Mrhl

109 possibly through RNA-DNA-DNA triplex formation. Our study delineates lncRNA Mrhl as a

110 chromatin regulator of cellular differentiation and development genes in mESCs, probably acting

111 to maintain the cells in a more primed state readily responsive to appropriate differentiation cues.

\section{Results}

\section{Mrhl is a nuclear-localized, chromatin bound moderately stable lncRNA in mESCs}

115 We analyzed poly (A) RNA-Seq datasets from the ENCODE database and observed that Mrhl is 116 expressed predominantly in the embryonic stages of tissues of various lineages (Figure 1-

117 supplementary figure 1). In the brain, heart and lung, Mrhl is expressed all throughout different

118 stages of embryos whereas its expression is almost nil in the postnatal stages. However, in the

119 liver and the kidney, Mrhl expression is down regulated but not completely abrogated in the 120 postnatal stages. From E8.5 onwards, the mouse embryo undergoes a surge of differentiation, 121 cell specification and organogenesis phenomena. Our data analysis suggested that Mrhl might 122 have a selective role to play in these processes in the context of mouse embryonic development. 123 To address this, we used mESCs as our model system of study. RNA FISH revealed Mrhl to be 
124 expressed primarily in the nulcei of mESCs (Figure 1A). Biochemical fractionation further 125 validated Mrhl to be present in the nuclear fraction, specifically the chromatin fraction in mESCs 126 (Figure 1B, C). We next addressed if Mrhl was actually associated with the chromatin for which 127 we performed H3 ChIP followed by qPCR and observed significant enrichment of Mrhl in H3 128 bound chromatin (Figure 1D). To further understand the functional relevance of Mrhl in mESCs, 129 we performed an assay for RNA half-life and we found Mrhl to display moderate stability with a 130 half-life of 2.73 hours (Figure 1E). Our observations herewith prompted us to investigate further 131 the functional roles of Mrhl in mESCs.

133 Differentiation assay, knockdown and transcriptome analyses reveal Mrhl to regulate 134 development and differentiation circuits in mESCs

135 We next differentiated the mESCs into embryoid bodies and very interestingly observed that 136 Mrhl was preferentially up regulated at days 4 and 6 of embryoid body formation (Figure 2A). 137 In perspective of the negative feedback regulation between Mrhl and WNT signaling in 138 spermatogonial progenitors and of WNT signaling contributing to mESC physiology (Atlasi et 139 al., 2013; Price et al., 2013; Sokol, 2011), we questioned whether Mrhl would function through 140 similar mechanisms in this context as well. We performed shRNA mediated knockdown of Mrhl 141 in mESCs and scored for its levels using RNA FISH followed by the status of $\beta$-CATENIN 142 localization by IF. We observed that in cells where Mrhl was depleted with high efficiency, $\beta$ 143 CATENIN was still localized at the membrane indicating non-activation of the WNT pathway 144 (Figure 2B). Furthermore, p68 IP revealed that Mrhl does not interact with p68 in mESCs 145 (Figure 2C). Keeping these observations in mind, we performed transient knockdown of Mrhl in 146 mESCs using four independent constructs, two of which (referred to as sh. 1 and sh. 4 147 henceforth) showed us an average down regulation of 50\% (Figure 2D) and subjected the 148 scrambled (scr.) and sh.4 treated cells to analysis by RNA-Seq. A quick comparison of the 149 FPKM values for Mrhl obtained in our analysis versus those reported in the ENCODE database 150 as well as of scr. versus sh.4 displayed Mrhl to be a low abundant lncRNA and confirmed our 151 knockdown efficiency respectively (Figure 2- supplementary figure 2A). Furthermore, we 152 observed that the expression of pluripotency factors OCT4 (OCT), SOX2 and NANOG were not 153 affected upon Mrhl knockdown in mESCs (Figure 2- supplementary figure 2B). We obtained a 154 total of 1143 genes which were dysregulated in expression with 729 being down regulated and 
155414 being up regulated in expression (Figure 2E) and we refer to them as the differentially 156 expressed genes (DEG, Supplementary File 1). The DEG majorly belonged to the class of 157 protein-coding genes and transcription factors with an interesting proportion belonging to 158 lincRNAs and antisense RNAs as well. Gene ontology (GO) analysis revealed diverse molecular 159 functions such as binding (23.6\%), catalytic activity (18.3\%), receptor activity (8.8\%) and signal 160 transducer activity (7.4\%) and biological processes such as cellular processes (40.9\%), biological 161 regulation (15.8\%), metabolic process (25.7\%), developmental process $(11.7 \%)$ and multicellular 162 organismal process (10.7\%) to be affected (Figure 2F). We next performed a GO enrichment 163 analysis with a p-value $<0.05$ to understand if one or more of the perturbed processes/pathways 164 were statistically over represented over the others and we found positive regulation of 165 developmental processes and positive regulation of multicellular organismal processes to be two 166 such enriched perturbed processes (Figure 2G). Other processes such as protein metabolic 167 processes, lipid metabolic processes, phosphate metabolic processes, protein modification 168 processes and MAPK cascade were also amongst the GO enriched list of processes. We then 169 performed Fisher's exact test in the PANTHER interface with a p-value $<0.001$ and obtained 170 several interesting GO categories to be further enriched and represented such as cell-cell 171 signaling, ion transport, synaptic transmission, response to endogenous stimuli, ectoderm 172 development, anion transport, cell-cell adhesion and neuromuscular synaptic transmission 173 (Supplementary Table 1). The category of developmental processes (GO:0032502, 174 Supplementary File 2) posed as the most interesting one since it has appeared in both the 175 enrichment analyses and possessed the maximum number of perturbed genes i.e., 60 with a 176 significant $\mathrm{p}$-value of 6.44E-05. We examined the DEG belonging to this category and found that 177 they belonged to two broad groups of lineage-specific TFs and cell adhesion/receptor activity. 178 The former group comprised genes encoding factors involved in neuronal lineage, hematopoietic 179 and vascular lineage, cardiac lineage, skeletal lineage, mesodermal lineage and pancreatic 180 lineage (Supplementary Table 2A) whereas the latter group consisted of genes responsible for 181 such functions as migration, axon guidance, signaling, growth and differentiation, structural roles 182 and cellular proliferation amongst others (Supplementary Table 2B). From our assays and 183 analyses herewith, we conclude that Mrhl majorly acts to regulate differentiation and 184 development related genes and processes in mESCs. Also, we compared the DEG in Mrhl 185 knockdown conditions in mESCs and GC1-Spg spermatogonial progenitors and made two 
observations: firstly, the perturbed transcriptome is vastly different, emphasizing the contextdependent role of Mrhl and secondly, about 25 genes were in common between the two datasets, suggesting some common target genes of regulation for Mrhl across developmental model systems (Figure 2- supplementary figure 2C).

Gene co-expression and TF interaction analyses show unique networks to be coordinated

193 In order to organize the perturbed transcriptome under conditions of Mrhl knockdown in mESCs 194 into functional and biologically relevant modules (W. Chen et al., 2018; X. Chen et al., 2016), 195 we performed hierarchical clustering of the DEG and visualized the resultant clusters or modules 196 with Cytoscape (Figure 3A). We obtained nine such co-expression modules. We then interrogated each of the modules for functional enrichment with GeneMania tool and observed diverse functions to be co-regulated by these groups of genes such as ion channel and transporter activities for clusters 4 and 5, nervous system functions for cluster 6, immune system processes

200 for cluster 7 and responses to xenobiotic stimuli for cluster 8. Clusters 2 and 3 had varied 201 functional enrichments whilst clusters 1 and 9 did not show any of such functional 202 representations. These analyses further support our earlier observations all of which suggest that 203 in mESCs, Mrhl acts to primarily modulate development and differentiation related processes.

204 We also performed a TF-TF interaction analysis to understand the potential cross-talk between 205 the dysregulated set of TFs (Figure 3-Supplementary File 3) and to identify a master TF 206 through which Mrhl might be acting to regulate the TF network. TFs have been implicated often 207 in determining cellular states or fates (Dunn, Martello, Yordanov, Emmott, \& Smith, 2014; 208 Goode et al., 2016). A gene ontology analysis of the perturbed TFs revealed metabolic processes 209 and developmental processes to be over represented in function (Figure 3- supplementary 210 figure 3A). A heat map was generated for delineating the potential TF network by scanning the 211 promoter sequence of each TF with the motif for each TF (Fig. 3B). RUNX2 was obtained as a 212 potential master TF since it had the maximum number of motifs for binding across the promoters 213 of all the other TFs followed by ERG (Figure 3- supplementary figure 3B). Based on this 214 logic, a simplified TF hierarchy was established using STRING wherein we observed RUNX2 to 215 be at the top of the hierarchy with RB1, ERG, FEV, SMAD9 and HEYL being in the first tier 216 (Figure 3C) and undergoing regulation via RUNX2, although their direct regulation by Mrhl 
cannot be ruled out. Thus, we report a novel TF network or hierarchy operating in mESCs in the

218 context of Mrhl. Furthermore, since all the TFs are involved in the specification of one of the

219 three lineages, the observations herewith further emphasize on Mrhl acting to control cell fate

220 specification and differentiation related circuits in mESCs.

\section{Stable knockdown of Mrhl in mESCs shows aberrance in lineage specification}

223 Towards understanding the phenotypic implications of Mrhl depletion in mESCs and of our 224 transcriptome analyses, we generated stable knockdown lines for Mrhl sh.4 and scr. control. Our 225 initial characterization of the stable knockdown cells showed a knockdown efficiency of 50\% 226 (Figure 4A), no change in the pluripotency markers Oct 4, Sox2 and Nanog (Figure 4B,C and 227 Figure 4-supplementary figure 4A) as well as no differences in the alkaline phosphatase 228 expression levels (Figure 4-supplementary figure 4B) in the knockdown versus control lines. 229 Since a couple of cell adhesion genes were present amongst the DEG, we performed IF for E230 CADHERIN and F-ACTIN. A comparison of the staining intensities revealed no significant 231 changes in cell adhesion properties between knockdown and control mESCs (Figure 4D and 232 Figure 4-supplementary figure 4C). These observations corroborate with our transcriptome 233 data. Next, keeping in mind our earlier conclusions and the observation that Mrhl is up regulated 234 in expression during embryoid body differentiation, we subjected the knockdown and control 235 cells to differentiation by the formation of embryoid bodies. Interestingly, we observed that over 236 days 2 to 8 of differentiation, there was a marked aberrance in the specification of lineages, 237 specifically the ectoderm and mesoderm lineages (Figure 4E, F). For the ectoderm lineage, there 238 appears to be premature specification in the knockdown cells at day 2 with subsequent loss in 239 maintenance of the lineage at days 6 and 8. The mesoderm lineage appears to be under-specified 240 from the beginning of differentiation with some expression of the marker $\mathrm{T}$ at day 6 in the 241 knockdown cells These observations imply that Mrhl is required in mESCs to undergo proper 242 specification of early lineages, majorly the ectoderm and mesoderm lineages, although it might 243 not have a specific role in mESCs per se in the absence of differentiation cues.

246 In order to further delineate the mechanism by which Mrhl regulates differentiation and 247 development related genes and processes in mESCs, we performed genome-wide chromatin 
occupancy studies through ChIRP-Seq since we have demonstrated Mrhl to be a chromatin bound lncRNA in mESCs. We obtained a total of 21,997 raw peaks and after keeping a cutoff value of 5-fold enrichment, we obtained 21,282 peaks (Figure 5A, Supplementary File 4), emphasizing the significant and widespread chromatin occupancy of Mrhl in mESCs. The peak lengths and fold changes appear to be distributed equally across all the chromosomes (Figure 5supplementary figure 5A, B). An annotation of the enriched peaks showed us that diverse regions including intronic, intergenic and promoter regions of genes as well as repeat elements undergo physical association with Mrhl (Figure 5B). Next, we overlapped the peaks from ChIRP-Seq and the DEG from RNA-Seq to understand what proportion of the dysregulated genes upon Mrhl knockdown is regulated by it at the chromatin level. In this regard, we have used $-10 \mathrm{~kb}$ upstream of transcription start site (TSS) and $+5 \mathrm{~kb}$ downstream of TSS of genes as our domain of target gene regulation by Mrhl which narrowed down the number of peaks to 3412. The overlap analysis revealed 71 genes which are physically occupied and are also regulated by Mrhl at the chromatin level (Figure 5C, Supplementary File 5). We further examined the 71 genes in detail and found a subset of six genes i.e., RUNX2, SIX2, DLX3, HOXB7, POU3F2 and FOXP2 to be of noticeable important in terms of being firstly, lineage determining or development associated transcription factors and secondly, being physically occupied by Mrhl at the promoter (Supplementary Table 3A).

A recently established mechanism of chromatin-mediated target gene regulation by lncRNAs is via the formation of RNA-DNA-DNA triple helical structures (Mondal et al., 2015; PostepskaIgielska et al., 2015; S. Wang et al., 2018). To delve deeper into the exact mechanism of chromatin-mediated gene regulation by Mrhl at the promoter of the aforesaid developmental loci, we hypothesized triplex formation by Mrhl at these loci. For this, we selected a subset of the six genes i.e., RUNX2, HOXB7, FOXP2 and POU3F2. Their roles in governing the development of specific lineages such as the osteoblast lineage [RUNX2 (Komori, 2002)], neuronal lineage and

273 brain development [FOXP2 (Chiu et al., 2014; Tsui, Vessey, Tomita, Kaplan, \& Miller, 2013), 274 POU3F2 (Y. J. Lin et al., 2018; Urban et al., 2015)) or having multiple functions during development [HOXB7 (Candini et al., 2015; Klein, Benchellal, Kleff, Jakob, \& Ergun, 2013)]

276 have been widely established. We first performed a search for motifs for binding to target 277 chromatin loci by Mrhl which led to the identification of three distinct motifs with motif 1 being 
total number of peaks. (Figure 5D and supplementary table 3B). Next, we analyzed the promoters of the aforementioned genes corresponding to the region where ChIRP-Seq peaks were obtained for the presence of one or more of the three motifs by FIMO in MEME suite followed by potential triplex formation at those sites using the Triplexator program. We observed the presence of only one motif (motif 3) at the Mrhl occupied region in POU3F2, motifs 1, 2 and 3 in FOXP2 and again motif 3 in RUNX2 and HOXB7. Interestingly, triplex prediction revealed triplex forming potential at two different sites in POU3F2, one lying within the motif sequence whereas in FOXP2 and RUNX2, potential triplex forming sites were found immediately adjacent to the motif sequences. HOXB7, however, did not show propensity for triplex formation within the Mrhl occupied region (Figure 5E, Supplementary table 3C, Supplementary File 6). In lieu of these observations, we conclude that Mrhl regulates key lineage-specific TFs at the chromatin possibly through triple helix formation to regulate differentiation of mESCs.

\section{Discussion}

293 Regulation of pluripotency and/or differentiation phenomena in embryonic stem cells by 294 IncRNAs in combination with their extensive context-dependent roles poses them as novel therapeutic targets in the context of regenerative medicine. Linc-RoR mediates the formation of human induced pluripotent stem cells (Loewer et al., 2010) and contributes to human embryonic stem cell self-renewal (Y. Wang et al., 2013) whereas lncRNA Cyrano is involved in maintenance of pluripotency of mESCs (Smith, Starmer, Miller, Sethupathy, \& Magnuson, 2017). In parallel, linc-RoR has been implicated in osteogenic differentiation of mesenchymal stem cells (Feng et al., 2018) whilst Cyrano has been shown to function in conjunction with other non-coding RNAs to regulate neuronal activity in the mammalian brain (Kleaveland, Shi, Stefano, \& Bartel, 2018) as well as neurodevelopment in zebrafish (Sarangdhar, Chaubey, Srikakulam, \& Pillai, 2018). In our current study, we have characterized and addressed the functional implications of lncRNA Mrhl, previously shown to regulate male germ cell meiotic commitment, in mESC circuitry to understand its role in development and differentiation. The role of nuclear lncRNAs in coordinating and controlling gene expression at a genome-wide level through a myriad of mechanisms is well known, amongst which regulation of chromatin 2015; Sun, Hao, \& Prasanth, 2018). 
310 LncRNA Mrhl depletion majorly dysregulates pathways and processes in mESCs which are

311 related to lineage-specific development and differentiation and which are largely distinct from

312 the perturbed gene set in spermatogonial progenitors. This emphasizes the context-dependant

313 role of Mrhl as a molecular player of the cellular system. This is further supported by lack of

314 association of Mrhl with p68 or absence of regulation of WNT signaling in mESCs as we have

315 shown in our studies. In perspective, it would be interesting to address the protein interaction

316 partners of Mrhl in mESCs, especially to understand in greater depth how Mrhl mediates

317 regulation at target genes.

319 An intriguing point to note is absolutely no perturbation of pluripotency status of mESCs upon 320 Mrhl knockdown rather disruption of lineage specification in embryoid bodies. These 321 observations suggest Mrhl to be involved in specifying a primed state of the mESCs wherein 322 they can undergo balanced specification of lineages upon obtaining differentiation cues. Other 323 disrupted pathways such as ion transport which have been recurrent in all systems analyses 324 would be an interesting aspect to address in the future. The aforesaid conclusions are further 325 supported by the fact that Mrhl is up regulated in expression at days 4 and 6 during embryoid 326 body differentiation, suggesting it as a regulator of differentiation programs in mESCs and 327 explaining the aberrance in lineage specification upon differentiation of Mrhl knockdown stable 328 mESCs. The lack of any effect on the endoderm lineage during in vitro differentiation of the 329 stable knockdown cells is explainable from an analysis of GO:0032502 wherein in vast majority 330 only ectoderm and mesoderm related genes were observed to be dysregulated. Furthermore, in 331 our ENCODE data analysis of organs, Mrhl was observed to be expressed predominantly in 332 embryonic stages of organs of various lineages such as the brain (ectoderm), kidney, testes 333 (mesoderm) and lung, liver (endoderm). An interrogation of Mrhl expression in the recently 334 released Mouse Organogenesis Cell Atlas (Cao et al., 2019) showed Mrhl to be expressed in 335 progenitor cell types of various tissues. This can only give us an insight about the involvement of 336 Mrhl not only in the early stages of germ layer specification but in the later stages of 337 organogenesis as well, although the exact functions in the latter need to be still addressed.

338 The regulation of a novel TF network in mESCs by Mrhl comprising mostly lineage-determining

339 TFs is an exciting observation. TFs act to govern gene expression programs defining particular 340 cellular states, more so in association with other TFs in a network (Dore \& Crispino, 2011; 
341 Niwa, 2018). LncRNAs often integrate into such networks by regulating TFs individually or via 342 a master $\mathrm{TF}(\mathrm{s})$ resulting in downstream regulation of gene expression (Herriges et al., 2014; Yo 343 \& Runger, 2018). The TF network operating in mESCs under the regulation of Mrhl has 344 RUNX2 at the top of the hierarchy posing it as a master TF in the hierarchy and being potentially 345 regulated by Mrhl directly through triplex formation at the chromatin level. Amongst the 71 346 genes overlapping between the DEG and the ChIRP-Seq reads, RUNX2, SIX2 and HOXB7 347 belong to a common group of the aforesaid set and the TF network. The absence of triplex 348 formation sites in HOXB7 in spite of the presence of Mrhl binding motifs in its promoter further 349 strengthens the hypothesis that Mrhl might be regulating the entire network through RUNX2. 350 Additionally, FOXP2 and POU3F2 although not a part of the TF network, display triplex 351 forming potential within the Mrhl occupied regions. These observations suggest an interesting 352 mechanism wherein Mrhl regulates differentiation programs in mESCs through direct regulation 353 of relevant TFs at their promoters.

355 A further analysis of our transcriptome studies herewith shows a significant over representation 356 of dysregulated genes and processes belonging to neuronal lineage. Ectoderm development was 357 one of the enriched processes in the Fisher's exact test and $\sim 20 \%$ of the dysregulated genes in 358 GO: 0032502 belonged to neuronal lineage development related functions. In the gene co359 expression analysis, nervous system emerged as one of the perturbed clusters. Furthermore, Mrhl 360 is predicted to regulate an important neuronal TF such as POU3F2 directly at the chromatin 361 level. Whilst our phenotype analysis of the stable knockdown cells showed perturbations in early 362 specification of the ectoderm and mesoderm lineages, further investigations of the role of Mrhl 363 in specifying more specialized lineages such as the neuronal lineage would be an interesting 364 aspect of study.

LncRNAs have been implicated widely for their contributions to embryonic stem cell 367 differentiation, cell fate specification, organogenesis and development through a diverse array of 368 mechanisms (Grote \& Herrmann, 2015; Perry \& Ulitsky, 2016; Sarropoulos, Marin, Cardoso369 Moreira, \& Kaessmann, 2019). In our studies we have characterized lncRNA Mrhl and its 370 functional significance in mESC towards decoding its role in developments. We show Mrhl to 371 regulate downstream genes and processes involved in differentiation and lineage specification 
372 that was reflected in our phenotype studies. A major finding of this study was its potential direct

373 chromatin mediated regulation of key TFs that mediate differentiation of stem cells into a

374 specific lineage. Overall, we establish lncRNA Mrhl to be a mediator of differentiation and cell

375 fate specification events in mESCs.

376

377

378

379

380

381

382

383

384

385

386

387

388

389

390

391

392

393

394

395

396

397

398

399

400

401

402 
Materials and Methods

\section{Cell lines, antibodies, plasmids and chemicals}

405 E14tg2a feeder independent mESC line was a kind gift from Prof. Tapas K. Kundu's lab 406 (JNCASR, India). mESCs were maintained on $0.2 \%$ gelatin coated dishes in mESC medium 407 containing DMEM, high glucose, 15\% FBS, 1X non-essential amino acids, $0.1 \mathrm{mM} \beta-$ 408 mercaptoethanol and 1X penicillin-streptomycin. HEK293T cells (ATCC, U.S.A) were 409 maintained in DMEM, 10\% FBS and 1X penicillin-streptomycin.

410 The antibodies used in this study are as follows: Anti-GAPDH (Abeomics, ABM22C5), anti-H3 411 (Abcam, ab46765), anti $\beta$-CATENIN (Abcam), anti p68 (Novus Biologicals), anti-OCT4 412 (Abcam, ab27985).

413 Scrambled and Mrhl shRNA plasmids 1, 2, 3 and 4 were custom made from Sigma in the 414 pLKO.1-Puro-CMV-tGFP vector backbone. The sequences of the shRNAs are as follows:

415 Mrhl shRNA\#1: 5'GCACATACATACATACACATATATT 3', Mrhl shRNA\#4: 416 5'GGAGAAACCCTCAAAAGTATT 3'.

417 All fine chemicals were obtained from Sigma (unless otherwise mentioned), gelatin was obtained 418 from Himedia and FBS was obtained from Gibco (Performance Plus, US Origin).

Protocols for mESC differentiation, transfection and cell assays

421 For embryoid body (EB) differentiation, E14tg2a cells were trypsinized using $0.05 \%$ trypsin and $4222.5 \times 10^{5}$ cells were plated onto $35 \mathrm{~mm}$ bacteriological grade dishes (Tarsons) in EB 423 differentiation medium containing DMEM, 10\% FBS, $0.1 \mathrm{mM} \beta$-mercaptoethanol and 1X 424 penicillin-streptomycin. EBs were harvested at different time points and processed accordingly 425 for further analysis.

426 All transfections for E14tg2a cells were performed using Trans IT-X2 reagent (Mirus, MIR 427 6003) as per the manufacturer's protocol. For transient knockdown analysis, cells were harvested 42848 hours post-transfection. Transfections for HEK293T cells were performed using 429 Lipofectamine 2000 (Thermo Fisher Scientific) as per the manufacturer's protocol.

430 For measurement of half-life of Mrhl, E14tg2a cells, at a confluency of $\sim 80-90 \%$, were treated 431 with $10 \mu \mathrm{M}$ actinomycin D (Sigma, A9415). Cells were harvested at different time points for 432 further analysis.

433 Alkaline phosphatase assay was performed as per the manufacturer's protocol (Sigma, 86R). 


\section{Generation of stable knockdown lines}

435 Stable mESC knockdown lines for Mrhl were generated in E14tg2a cells as per the protocol of 436 Pijnappel et al (Pijnappel, P.A. Baltissen, \& Timmers, 2013) with some modifications Briefly, 437 viral particles were generated in HEK293T cells by transfection of $5 \mu \mathrm{g}$ scrambled or Mrhl 438 shRNA plasmids, $2.5 \mu \mathrm{g}$ pSPAX2, $1.75 \mu \mathrm{g}$ pVSVG and $0.75 \mu \mathrm{g}$ pRev. The media containing 439 viral particles was harvested 48 hours after transfection and centrifuged at 4,000 rpm for 5 440 minutes to remove cellular debris. Fresh mESC medium was added and harvested after an 441 additional 24 hours to collect second round of viral particles. The viral supernatants were stored 442 in $-80^{\circ} \mathrm{C}$ if necessary. E14tg2a cells were plated such that they reached a confluency of $\sim 60-70 \%$ 443 on the day of transduction. The viral supernatant was mixed with $8 \mu \mathrm{g} / \mathrm{ml}$ DEAE-dextran and 4441000 units/ml ESGRO (Merck Millipore) and added directly to the E14tg2a cells. Transduction 445 was performed for 24 hours with the first round of viral particles and an additional 24 hours with 446 the second round of viral particles. The transduced cells were then subjected to puromycin 447 selection $(1.5 \mu \mathrm{g} / \mathrm{ml}$ puromycin) for a week.

\section{RNA fluorescent in situ hybridization (FISH) and immunofluorescence (IF)}

450 RNA FISH followed by IF was performed as per the protocol of de Planell-Saguer et al (de 451 Planell-Saguer, Rodicio, \& Mourelatos, 2010) with modifications. The probes used for RNA 452 FISH studies were Cy5 labelled locked nucleic acid probes procured from Exiqon (reported in 453 (Arun et al., 2012)). Briefly, cells were grown on gelatin coated coverslips. EBs were fixed in $4544 \%$ paraformaldehyde for $7-8$ hours at $4^{\circ} \mathrm{C}$ followed by equilibration in $20 \%$ sucrose solution 455 overnight and embedded in tissue freezing medium (Leica). The embedded tissues were then 456 cryo-sectioned and collected on Superfrost slides (Fisher Scientific). For cells, a brief wash was 457 given with 1X PBS (phosphate buffered saline, $\mathrm{pH} 7.4$ ) followed by fixation with $2 \%$ 458 formaldehyde for 10 minutes at room temperature. The cells were then washed with $1 \mathrm{X}$ PBS 459 three times for 1 minute each and permeabilization buffer (1X PBS, 0.5\% Triton X-100) was 460 added for 5 minutes and incubated at $4^{\circ} \mathrm{C}$. The permeabilization buffer was removed and cells 461 were washed briefly with $1 \mathrm{X}$ PBS for three times at room temperature. For tissue sections, 462 antigen retrieval was performed by boiling the sections in $0.01 \mathrm{M}$ citrate buffer (ph 6) for 10 463 minutes. The sections were allowed to cool, washed in distilled water three times for 5 minutes 464 each and then in $1 \mathrm{X}$ PBS for 5 minutes, each time with gentle shaking. 
For FISH, samples were blocked in prehybridization buffer [3\% BSA, 4X SSC (saline sodium citrate, $\mathrm{pH}$ 7)] for 40 minutes at $50^{\circ} \mathrm{C}$. Hybridization (Mrhl probes tagged with $\mathrm{Cy} 5$, final concentration $95 \mathrm{nM}$ ) was performed with prewarmed hybridization buffer (10\% dextran sulphate in $4 \mathrm{X} \mathrm{SSC}$ ) for 1 hour at $50^{\circ} \mathrm{C}$. After hybridization, slides were washed four times for 6 minutes each with wash buffer I (4X SSC, $0.1 \%$ Tween-20) at $50^{\circ} \mathrm{C}$ followed by two washes with wash buffer II (2X SSC) for 6 minutes each at $50^{\circ} \mathrm{C}$. The samples were then washed with wash buffer III (1X SSC) once for 5 minutes at $50^{\circ} \mathrm{C}$ followed by one wash with $1 \mathrm{X}$ PBS at room temperature. For tissue sections, all washes were performed as mentioned above with a time of 4 minutes for buffers I-III.

474 For IF, samples were blocked with IF blocking buffer (4\% BSA, 1X PBS) for 1 hour at $4{ }^{\circ} \mathrm{C}$. 475 Primary antibody solution (2\% BSA, 1X PBS) was prepared containing the appropriate dilution of desired primary antibody and the samples were incubated in it for 12 hours at $4^{\circ} \mathrm{C}$. Next day, the samples were washed with IF wash buffer (0.2\% BSA, 1X PBS) three times for 5 minutes each with gentle shaking. The samples were incubated in secondary antibody for 45 minutes at room temperature and washed with $1 \mathrm{X}$ PBS three times for 10 minutes each with gentle shaking. The samples were finally mounted in mounting medium containing glycerol and DAPI.

\section{Biochemical fractionation}

\section{Cell fractionation}

484 Approximately 5-10 million cells were lysed using lysis buffer (0.8 M sucrose, $150 \mathrm{mM} \mathrm{KCl,} 5$ $485 \mathrm{mM} \mathrm{MgCl}_{2}, 6 \mathrm{mM} \beta$-mercaptoethanol and 0.5\% NP-40) supplemented with 75 units/ml RNAse 486 inhibitor (Thermo Fisher Scientific) and 1X mammalian protease inhibitor cocktail (Roche) 487 and centrifuged at $10,000 \mathrm{~g}$ for 5 minutes at $4{ }^{\circ} \mathrm{C}$. The supernatant containing cytoplasmic 488 fraction was mixed with 3 volumes of TRIzol for RNA extraction or with Laemmli buffer for 489 western blotting as described later. The resultant pellet was washed twice with lysis buffer and 490 was subjected to RNA or protein extraction.

\section{Sub-nuclear fractionation}

492 Approximately 10 million cells were lysed with hypotonic lysis buffer (10 mM Tris- $\mathrm{HCl}$ ph 7.5, $49310 \mathrm{mM} \mathrm{NaCl}, 3 \mathrm{mM} \mathrm{MgCl} 2,0.3 \% \mathrm{v} / \mathrm{v} \mathrm{NP}-40$ and 10\% v/v/ glycerol) supplemented with RNAse 494 inhibitor and mammalian protease inhibitor cocktail and centrifuged at 1,000 $\mathrm{g}$ for 5 minutes at 4 $495{ }^{\circ} \mathrm{C}$. The supernatant comprising the cytoplasmic fraction was kept aside and the nuclear pellet 
was washed twice with hypotonic lysis buffer. The nuclear pellet was then resuspended in modified Wuarin-Schibler buffer (10 mM Tris-HCl pH 7.0, 4 mM EDTA, 300 mM NaCl, 1 M urea and 1\% NP-40) supplemented with RNAse inhibitor and mammalian protease inhibitor cocktail and vortexed for 10 minutes. Nucleoplasmic and chromatin fractions were separated by centrifugation at $1,000 \mathrm{~g}$ for 5 minutes at $4{ }^{\circ} \mathrm{C}$. The chromatin pellet was resuspended in sonication buffer $(20 \mathrm{mM}$ Tris- $\mathrm{HCl} \mathrm{pH} 7.5,150 \mathrm{mM} \mathrm{NaCl}, 3 \mathrm{mM} \mathrm{MgCl}$, $0.5 \mathrm{mM}$ PMSF, 75 units/ml RNAse inhibitor) and sonicated for 10 minutes. The chromatin was then obtained as the supernatant following centrifugation at $18,000 \mathrm{~g}$ for 10 minutes at $4{ }^{\circ} \mathrm{C}$ to remove all debris. The resultant nucleoplasmic and chromatin fractions were then subjected to RNA or protein extraction as described later.

\section{Immunoprecipitation (IP)}

508 p68 IP

509 Cells were lysed in hypotonic lysis buffer (10 mM Tris- $\mathrm{HCl}$ ph 7.5, $10 \mathrm{mM} \mathrm{NaCl,} 3 \mathrm{mM} \mathrm{MgCl}_{2}$, $510 \quad 0.3 \%$ NP-40, $10 \%$ glycerol) supplemented with RNase inhibitor, mammalian protease inhibitor 511 cocktail and $1 \mathrm{mM}$ PMSF. Nuclei were pelleted down at $1200 \mathrm{~g}$ for 10 minutes at $4^{\circ} \mathrm{C}$ and 512 subsequently lysed in nuclear lysis buffer $(150 \mathrm{mM} \mathrm{KCl}, 25 \mathrm{mM}$ Tris pH 7.4, $5 \mathrm{mM}$ EDTA, $5130.5 \%$ NP-40) supplemented with RNase inhibitor, mammalian protease inhibitor cocktail and 514 PMSF. The debris was removed by centrifugation at $15,000 \mathrm{~g}$ for 10 minutes at $4^{\circ} \mathrm{C}$ and the 515 supernatant nuclear fraction was collected. To $1 \mathrm{mg}$ of the nuclear fraction containing proteins, 7 $516 \mu \mathrm{g}$ of either pre-immune serum or p68 antibody was added and incubated overnight at $4^{\circ} \mathrm{C}$. Next 517 day, the fraction was incubated with protein A dynabeads for 3 hours at $4^{\circ} \mathrm{C}$. The beads were 518 washed with wash buffer (20 mM Tris- $\mathrm{HCl} \mathrm{pH}$ 7.4, $2 \mathrm{mM} \mathrm{MgCl} 2,10 \mathrm{mM}$ KCL, $150 \mathrm{mM} \mathrm{NaCl}$, $51910 \%$ glycerol, $0.2 \%$ NP-40) supplemented with RNase inhibitor, mammalian protease inhibitor cocktail and PMSF. Subsequently, the beads were washed twice with wash buffer (as above with 0.5\% NP-40) and collected. The beads were then resuspended either in RNAiso Plus and 522 subjected to RNA isolation for qRT-PCR analysis or in Laemmli buffer and resolved on a 10\% 523 SDS-PAGE gel for western blotting analysis as described later.

\section{Chromatin IP}

525 Chromatin IP (ChIP) was performed as per Cotney and Noonan's protocol (Cotney \& Noonan, 2015). Approximately 6-7 million cells were cross-linked with $1 \%$ formaldehyde for 10 minutes. 
527 The reaction was quenched with $125 \mathrm{mM}$ glycine for 5 minutes and washed twice with ice-cold 528 1X PBS. Cells were lysed using hypotonic lysis buffer $(10 \mathrm{mM}$ Tris ph $7.5,10 \mathrm{mM} \mathrm{NaCl}, 3 \mathrm{mM}$ $\mathrm{MgCl}_{2}, 0.3 \% \mathrm{NP}-40$ and $10 \%$ glycerol) supplemented with RNAse inhibitor and mammalian

530 protease inhibitor cocktail. Nuclei were pelleted at $1200 \mathrm{~g}$ for 10 minutes at $4^{\circ} \mathrm{C}$ and resuspended 531 in nuclear lysis buffer $(0.1 \%$ SDS, $0.5 \%$ Triton X-100, 20mM Tris pH 7.5 and $150 \mathrm{mM} \mathrm{NaCl})$ 532 RNAse inhibitor and mammalian protease inhibitor cocktail. Resuspended nuclei were then 533 sonicated (Biorupter, 25 cycles) and 15 ug chromatin was incubated with either $4 \mu \mathrm{g}$ H3 534 antibody or pre-immune serum overnight at $4^{\circ} \mathrm{C}$. Antibody bound chromatin was then pulled 535 down using protein A dynabeads (Thermo Fischer Scientific) for 3 hours at $4^{\circ} \mathrm{C}$. The beads were 536 then washed sequentially with wash buffer I (nuclear lysis buffer), wash buffer II (nuclear lysis 537 buffer with $500 \mathrm{mM} \mathrm{NaCl})$ and wash buffer III (10mM Tris pH 8.0, 0.5\% NP-40, 0.5\% sodium 538 deoxycholate, 1mM EDTA), each supplemented with RNAse inhibitor and mammalian protease inhibitor cocktail for 5 minutes each. The beads were then either processed directly for western blotting or subjected to elution for 1 hour at $55^{\circ} \mathrm{C}$ in elution buffer $(100 \mathrm{mM} \mathrm{NaCl}, 10 \mathrm{mM}$ Tris $\mathrm{pH} 7.5,1 \mathrm{mM}$ EDTA, 0.5\% SDS) supplemented with $100 \mathrm{ug} / \mathrm{ml}$ proteinase K. The supernatant was then subjected to reverse cross-linking by heating for 10 minutes at $95^{\circ} \mathrm{C}$ and then taken forward for RNA isolation using TriZol (Ambion).

\section{Chromatin Isolation by RNA Purification (ChIRP)}

546 ChIRP was carried out according to the protocol of Chu et al (Chu, Quinn, \& Chang, 2012).

547 Anti-sense (As) DNA probes with BiotinTEG at 3' end was designed using the online probe 548 designer at single-molecule FISH online designer. As-DNA probes were designed for both 549 LncRNA Mrhl and LacZ for selective retrieval of RNA target by ChIRP. Cells were grown to 550 confluency and $\sim 80$ million cells were harvested to perform ChIRP. Cells were cross linked with $5511 \%$ glutaraldehyde to preserve RNA-Chromatin interactions and cell pellet was prepared. 552 Crosslinked cells were lysed to prepare cell lysate using freshly prepared lysis buffer (50 $\mathrm{mM}$ 553 Tris-Cl pH 7.0, 10 mM EDTA, $1 \%$ SDS) supplemented with 1mM PMSF, 1X mammalian 554 protease inhibitor cocktail (PI) and superase-in. The suspension was divided into $400 \mu l$ aliquots 555 and subjected immediately to sonication. Sonication was continued until the cell lysate was no 556 longer turbid. When lysate turned clear, $5 \mu$ lysate was transferred to a fresh eppendorf tube. 90 $557 \mu$ DNA Proteinase K (PK) buffer (100 mM NaCl, 10 mM Tris-Cl pH 7.0, 1 mM EDTA, $0.5 \%$ 
SDS) supplemented with $5 \mu \mathrm{PK}$ was added and incubated for $45 \mathrm{~min}$ at $55^{\circ} \mathrm{C}$. DNA was extracted with Diagenode microChIP DiaPure purification kit to check DNA size on 1\% agarose gel. If bulk of the DNA smear was $100-500 \mathrm{bp}$, sonication was assumed completed. Subsequent morning biotinylated DNA probes were hybridized to RNA and bound chromatin was isolated.

562 For a typical ChIRP sample using $1 \mathrm{ml}$ of lysate, 5\% was kept aside for RNA input and DNA input. Hybridization buffer $(750 \mathrm{mM} \mathrm{NaCl}, 1 \%$ SDS, $50 \mathrm{mM}$ Tris-Cl pH 7.0, $1 \mathrm{mM}$ EDTA, 15 $\%$ formamide) supplemented with 1mM PMSF, 1X PI and superase-in was added to each lysate tube. $100 \mathrm{pmol}$ of probe mix was added per $1 \mathrm{ml}$ chromatin $(1 \mu \mathrm{l}$ of $100 \mathrm{pmol} / \mu \mathrm{l}$ probe per $1 \mathrm{ml}$ chromatin). This was incubated for $4 \mathrm{hrs}$ at $37^{\circ} \mathrm{C}$ with shaking. $100 \mu \mathrm{C}-1$ magnetic beads were used per 100 pmol of probes. Beads were resuspended in original volume of lysis buffer supplemented with PMSF, PI and superase-in. After 4 hr hybridization reaction was completed, $60 \mu \mathrm{l}$ beads were added to each tube and incubated at $37^{\circ} \mathrm{C}$ for $30 \mathrm{~min}$ with shaking. The beads were then washed for five times with wash buffer (2× SSC, $0.5 \%$ SDS, 1 mM PMSF). At last wash, the beads were resuspended well. $100 \mu \mathrm{l}$ was set aside for RNA isolation and $900 \mu 1$ for

572 DNA isolation. All tubes were placed on DynaMag-2 magnetic strip and last traces of wash

573 buffer removed. RNA was isolated for further qRT-PCR analysis. LacZ was used as a negative 574 control. DNA was isolated and sent for high throughput sequencing in duplicates.

\section{RNA isolation and PCR}

Total RNA was isolated from cells or tissues using TRIzol (Thermo Fisher Scientific) for RNAsequencing and IP or using RNAiso Plus (Takara Bio) for analysis by qRT-PCR as per the manufacturer's protocol. All RNA samples were subjected to DNase treatment (NEB) and about 1-3.5 $\mu \mathrm{g}$ of the RNA was taken for cDNA synthesis using oligodT primers (Thermo Fisher Scientific), RevertAid reverse transcriptase (Thermo Fisher Scientific) and RNase inhibitor (Takara Bio). The cDNA was diluted 1:1 with nuclease free water and subjected to qRT-PCR using SyBr green mix (Takara) in real-time PCR machine (BioRad CFX96). All semiquantitative PCR was performed in thermal cycler machine (BioRad, Tetrad2) using Taq polymerase (Takara). 


\section{Systems analysis}

\section{RNA-Seq analysis}

591 E14tg2a cells treated with scrambled or Mrhl shRNA (shRNA 4) were subjected to RNA

592 isolation and quality check. RNA samples were then subjected to library preparation in 593 duplicates and sequenced on Illumina Hi-Seq 2500 platform. mm10 Genome was downloaded 594 from GENCODE and indexed using Bowtie2-build with default parameters. Adapter ligation 595 was done using Trim Galore (v 0.4.4) and each of the raw Fastq files were passed through a 596 quality check using the FastQC. PCR duplicates were removed using the Samtools 1.3.1 with the 597 help of 'rmdup' option. Each of the raw files were then aligned to mm10 genome assembly using 598 TopHat with default parameters for paired-end sequencing as described in (Trapnell et al., 2012). 599 After aligning, quantification of transcripts was performed using Cufflinks and then Cuffmerge 600 was used to create merged transcriptome annotation. Finally differentially expressed genes were 601 identified using Cuffdiff. The threshold for DE genes was log2 (fold change) >1.5 for up 602 regulated genes and $\log 2$ (fold change) $<1.5$ for down regulated genes. The DE genes were 603 analyzed further using R CummeRbund package.

\section{GO enrichment analysis}

605 Gene Ontology (GO) analysis was performed in PANTHER (Thomas et al., 2003). Significant 606 enrichment test was performed with the set of differentially expressed genes in PANTHER and 607 Bonferroni correction method was applied to get the best result of significantly enriched 608 biological processes.

\section{Fisher's exact test}

610 Fisher's exact test was performed in PANTHER Gene Ontology (GO) where p-value significance 611 was calculated based on the ratio of obtained number of genes to the expected number of genes $612(\mathrm{O} / \mathrm{E})$ considering the total number of genes for the respective pathway in Mus musculus.

\section{Cluster analysis}

614 Hierarchical clustering method was performed using Cluster 3.0 (de Hoon, Imoto, Nolan, \& 615 Miyano, 2004). Gene expression data (FPKM of all samples i.e, scrambled and shRNA treated) 616 was taken and $\log 2$ transformed. Low expressed $(\mathrm{FPKM}<0.05)$ and invariant genes were 617 removed. Then genes were centered and clustering was performed based on differential 618 expression pattern of genes and fold change. Genes were grouped in 9 clusters and visualized as 
619 a network in Cytoscape (Shannon et al., 2003). Functional enrichment of each cluster was

620 performed using the Gene Mania Tool (Warde-Farley et al., 2010).

621 TF network analysis

622 Motifs were downloaded for all transcription factors from JASPAR (Mathelier et al., 2014) and

623 sequence of interest for each TF (1.5 kb upstream \& 500bp downstream of TSS) was extracted

624 using BedtoFasta of the Bedtools suite (Quinlan \& Hall, 2010). Then each motif was scanned

625 across the sequence of all TFs to create the table matrix that reflects the number of binding sites

626 for each TF across the other TFs using MEME suite (Bailey et al., 2009) with a e-value of 1E-04.

627 Finally the heatmap was generated from the table matrix using $\mathrm{R}$ 3.3.2. TFs were fed into

628 STRING (Jensen et al., 2009) to visualize the known interactions from the experimental data and

629 hierarchy was setup manually as per the interaction among given TFs (proteins).

\section{ChIRP-Seq analysis}

$631 \mathrm{~mm} 10$ Genome was downloaded from GENCODE and indexed using Bowtie2-build with default

632 parameters. Adapter ligation was done using Trim Galore (v 0.4.4) and each of the raw Fastq

633 files were passed through a quality check using the FastQC. PCR duplicates were removed using

634 the Samtools 1.3.1 with the help of 'rmdup' option. Each of the raw files was then aligned

635 to mm10 genome assembly using Bowtie 2 with default parameters for paired-end sequencing as

636 described in. Replicates of both control and treated were merged respectively. Peaks were called

637 using MACS2. Final peaks were selected giving the criteria of above 5-fold change and p value $638<0.05$.

\section{Mrhl Motif Prediction}

640 Motifs were identified using MEME, using the criteria of One Occurrence Per Sequence (OOPS) 641 and significance of 1E-04 for 21282 genomic loci. Sequence for each locus was extracted from $642 \mathrm{~mm} 10$ genome using bedtofasta of bedtools suite. After feeding sequences from 21282 genomic 643 loci obtained from MACS2, 3 significant motifs were identified.

\section{Triplex Prediction}

645 Sequence from the Mrhl occupied region (in addition extended upto +/- 25 bp) of selected genes 646 was used for Triplex prediction using the software Triplexator (Buske, Bauer, Mattick, \& Bailey, 647 2012) with default parameters. 
650 qRT-PCR primer sequences

\begin{tabular}{|l|l|l|}
\hline Gene Name & Forward Primer (5' to 3') & Reverse Primer (5' to 3') \\
\hline Oct 4 & ACCACCATCTGTCGCTTC & CCACATCCTTCTCTAGCC \\
\hline Sox 2 & GAGTGGAAACTTTTGTCCGAGA & GAAGCGTGTACTTATCCTTCTTCAT \\
\hline Nanog & AGGGTCTGCTACTGAGATGCTCTG & CAACCACTGGTTTTTCTGCCACCG \\
\hline Fgf5 & GTAGCGCGACGTTTTCTTCG & AATTTGGCTTAACACACTGGC \\
\hline Gata3 & GGCTACGGTGCAGAGGTATC & GATGGACGTCTTGGAGAAGG \\
\hline T & CAGCCCACCTACTGGCTCTA & CCCCTTCATACATCGGAGAA \\
\hline$\beta$-globin & CTCAAGGAGACCTTTGCTCA & AGTCCCCATGGAGTCAAAGA \\
\hline$\alpha-$ fetoprotein & CCTGTGAACTCTGGTATCAG & GCTCACACCAAAGCGTCAAC \\
& & \\
\hline Mrhl & TGAGGACCATGGCTGGACTCT & AGATGCAGTTTCCAATGTCCAAAT \\
\hline$\beta$-actin & AGGTCATCACTATTGGCAACG & TACTCCTGCTTGCTGATCCAC \\
\hline GAPDH & GGGAAATGAGAGAGGCCCAG & TACGGCCAAATCCGTTCACA \\
\hline U1snRNA & CTTACCTGGCAGGGGAGAT & CAGTCCCCCACTACCACAA \\
\hline SRA & TCCACCTCCTTCAAGTAAGC & GACCTCAGTCACATGGTCAACC \\
\hline
\end{tabular}

\section{Oligo Sequences for ChIRP-Seq}

653 Mrhl Oligo 1: 5' - AGTCAGATTACTGCTGGTCAGAACTAATAAACTCA-3'

654 Mrhl Oligo 2: 5' - CTGCTTCCTTCCTGGAATCAACAATAAAGCAGTTA-3'

655 Mrhl Oligo 3: 5'-ACTTCTTTCCAGTGACTGCAATTATCTTACAGAAGA-3'

656 Mrhl Oligo 4: 5'-TGAGTTTATTAGTTCTGACCAAGCAGTAATCTGACT-3'

657 Mrhl Oligo 5: 5'-TAACTGCTTTATTGTTGATTCCAGGAAGGAAGCAG-3'

658 Mrhl Oligo 6: 5'-TCTTCTGTAAGATAATTGCAGTCACTGGAAAGAAGT-3'

LacZ1: 5' - CCAGTGAATCCGTAATCATG-3'

661 LacZ2: 5'- TCACGACGTTGTAAAACGAC-3'

662

663

664 


\section{Competing Interests:}

667 The authors declare that they have no competing interests.

\section{Acknowledgements:}

670 We thank Prof. Tapas Kumar Kundu (JNCASR, India) for providing E14TG2a mESCs and Prof.

671 Maneesha Inamdar (JNCASR, India) for intellectual discussions. We thank Suma B.S of the

672 Confocal Imaging Facility, Dr. R.G Prakash of the Animal Facility and Anitha G. of the

673 Sequencing Facility at JNCASR, India. We thank Dhanur P. Iyer for initial help in

674 standardization of RNA FISH technique. M.R.S Rao acknowledges Department of Science and

675 Technology, Govt. of India for SERB Distinguished Fellowship and this work was financially

676 supported by Department of Biotechnology, Govt. of India (Grant Numbers: BT/01/COE/07/09 and DBT/INF/22/SP27679/2018). Debosree Pal thanks University Grants Commission and JNCASR, India for her PhD fellowship.

\section{References:}

1. Akhade, V. S., Arun, G., Donakonda, S., \& Rao, M. R. (2014). Genome wide chromatin occupancy of mrhl RNA and its role in gene regulation in mouse spermatogonial cells. RNA Biol, 11(10), 1262-1279. doi:10.1080/15476286.2014.996070

2. Akhade, V. S., Dighe, S. N., Kataruka, S., \& Rao, M. R. (2016). Mechanism of Wnt signaling induced down regulation of mrhl long non-coding RNA in mouse spermatogonial cells. Nucleic Acids Res, 44(1), 387-401. doi:10.1093/nar/gkv1023

3. Anguera, M. C., Ma, W., Clift, D., Namekawa, S., Kelleher, R. J., 3rd, \& Lee, J. T. (2011). Tsx produces a long noncoding RNA and has general functions in the germline, stem cells, and brain. PLoS Genet, 7(9), e1002248. doi:10.1371/journal.pgen.1002248

4. Ard, R., Allshire, R. C., \& Marquardt, S. (2017). Emerging Properties and Functional Consequences of Noncoding Transcription. Genetics, 207(2), 357-367. doi:10.1534/genetics.117.300095

5. Arun, G., Akhade, V. S., Donakonda, S., \& Rao, M. R. (2012). mrhl RNA, a long noncoding RNA, negatively regulates Wnt signaling through its protein partner Ddx5/p68 in mouse spermatogonial cells. Mol Cell Biol, 32(15), 3140-3152. doi:10.1128/mcb.00006-12

6. Atlasi, Y., Noori, R., Gaspar, C., Franken, P., Sacchetti, A., Rafati, H., . . . Fodde, R. (2013). Wnt signaling regulates the lineage differentiation potential of mouse embryonic stem cells through Tcf3 down-regulation. PLoS Genet, 9(5), e1003424. doi:10.1371/journal.pgen.1003424 
7. Bailey, T. L., Boden, M., Buske, F. A., Frith, M., Grant, C. E., Clementi, L., . . Noble, W. S. (2009). MEME SUITE: tools for motif discovery and searching. Nucleic Acids Res, 37(Web Server issue), W202-208. doi:10.1093/nar/gkp335

8. Ballarino, M., Cipriano, A., Tita, R., Santini, T., Desideri, F., Morlando, M., . . Bozzoni, I. (2018). Deficiency in the nuclear long noncoding RNA Charme causes myogenic defects and heart remodeling in mice. Embo j, 37(18). doi:10.15252/embj.201899697

9. Bergmann, J. H., Li, J., Eckersley-Maslin, M. A., Rigo, F., Freier, S. M., \& Spector, D. L. (2015). Regulation of the ESC transcriptome by nuclear long noncoding RNAs. Genome Res, 25(9), 1336-1346. doi:10.1101/gr.189027.114

10. Bruin, J. E., Saber, N., Braun, N., Fox, J. K., Mojibian, M., Asadi, A., . . Kieffer, T. J. (2015). Treating diet-induced diabetes and obesity with human embryonic stem cellderived pancreatic progenitor cells and antidiabetic drugs. Stem Cell Reports, 4(4), 605620. doi:10.1016/j.stemcr.2015.02.011

11. Buske, F. A., Bauer, D. C., Mattick, J. S., \& Bailey, T. L. (2012). Triplexator: detecting nucleic acid triple helices in genomic and transcriptomic data. Genome Res, 22(7), 13721381. doi:10.1101/gr.130237.111

12. Cajigas, I., Leib, D. E., Cochrane, J., Luo, H., Swyter, K. R., Chen, S., . . Kohtz, J. D. (2015). Evf2 lncRNA/BRG1/DLX1 interactions reveal RNA-dependent inhibition of chromatin remodeling. Development, 142(15), 2641-2652. doi:10.1242/dev.126318

13. Candini, O., Spano, C., Murgia, A., Grisendi, G., Veronesi, E., Piccinno, M. S., . . . Dominici, M. (2015). Mesenchymal progenitors aging highlights a miR-196 switch targeting HOXB7 as master regulator of proliferation and osteogenesis. Stem Cells, 33(3), 939-950. doi:10.1002/stem.1897

14. Cao, J., Spielmann, M., Qiu, X., Huang, X., Ibrahim, D. M., Hill, A. J., . . Shendure, J. (2019). The single-cell transcriptional landscape of mammalian organogenesis. Nature, 566(7745), 496-502. doi:10.1038/s41586-019-0969-x

15. Caudron-Herger, M., Pankert, T., Seiler, J., Nemeth, A., Voit, R., Grummt, I., \& Rippe, K. (2015). Alu element-containing RNAs maintain nucleolar structure and function. Embo j, 34(22), 2758-2774. doi:10.15252/embj.201591458

16. Caudron-Herger, M., \& Rippe, K. (2012). Nuclear architecture by RNA. Curr Opin Genet Dev, 22(2), 179-187. doi:10.1016/j.gde.2011.12.005

17. Cesana, M., Cacchiarelli, D., Legnini, I., Santini, T., Sthandier, O., Chinappi, M., . . . Bozzoni, I. (2011). A long noncoding RNA controls muscle differentiation by functioning as a competing endogenous RNA. Cell, 147(2), 358-369. doi:10.1016/j.cell.2011.09.028

18. Chen, W., Zhang, X., Li, J., Huang, S., Xiang, S., Hu, X., \& Liu, C. (2018). Comprehensive analysis of coding-lncRNA gene co-expression network uncovers conserved functional lncRNAs in zebrafish. BMC Genomics, 19(Suppl 2), 112. doi:10.1186/s12864-018-4458-7

19. Chen, X., Liu, B., Yang, R., Guo, Y., Li, F., Wang, L., \& Hu, H. (2016). Integrated analysis of long non-coding RNAs in human colorectal cancer. Oncotarget, 7(17), 2389723908. doi:10.18632/oncotarget.8192

20. Chiu, Y. C., Li, M. Y., Liu, Y. H., Ding, J. Y., Yu, J. Y., \& Wang, T. W. (2014). Foxp2 regulates neuronal differentiation and neuronal subtype specification. Dev Neurobiol, 74(7), 723-738. doi:10.1002/dneu.22166 
21. Chu, C., Quinn, J., \& Chang, H. Y. (2012). Chromatin isolation by RNA purification (ChIRP). J Vis Exp(61). doi:10.3791/3912

22. Cotney, J. L., \& Noonan, J. P. (2015). Chromatin immunoprecipitation with fixed animal tissues and preparation for high-throughput sequencing. Cold Spring Harb Protoc, 2015(2), 191-199. doi:10.1101/pdb.prot084848

23. de Hoon, M. J., Imoto, S., Nolan, J., \& Miyano, S. (2004). Open source clustering software. Bioinformatics, 20(9), 1453-1454. doi:10.1093/bioinformatics/bth078

24. de Planell-Saguer, M., Rodicio, M. C., \& Mourelatos, Z. (2010). Rapid in situ codetection of noncoding RNAs and proteins in cells and formalin-fixed paraffinembedded tissue sections without protease treatment. Nat Protoc, 5(6), 1061-1073. doi:10.1038/nprot.2010.62

25. Dore, L. C., \& Crispino, J. D. (2011). Transcription factor networks in erythroid cell and megakaryocyte development. Blood, 118(2), 231-239. doi:10.1182/blood-2011-04285981

26. Dunn, S. J., Martello, G., Yordanov, B., Emmott, S., \& Smith, A. G. (2014). Defining an essential transcription factor program for naive pluripotency. Science, 344(6188), 11561160. doi:10.1126/science. 1248882

27. Evans, M. J., \& Kaufman, M. H. (1981). Establishment in culture of pluripotential cells from mouse embryos. Nature, 292(5819), 154-156. doi:10.1038/292154a0

28. Faghihi, M. A., Modarresi, F., Khalil, A. M., Wood, D. E., Sahagan, B. G., Morgan, T. E., ... Wahlestedt, C. (2008). Expression of a noncoding RNA is elevated in Alzheimer's disease and drives rapid feed-forward regulation of beta-secretase. Nat Med, 14(7), 723730. doi:10.1038/nm1784

29. Fatima, R., Choudhury, S. R., Divya, T. R., Bhaduri, U., \& Rao, M. R. S. (2018). A novel enhancer RNA, Hmrhl, positively regulates its host gene, $\langle\mathrm{em}>\mathrm{phkb},</ \mathrm{em}>$ in Chronic Myelogenous Leukemia. bioRxiv, 378984. doi:10.1101/378984

30. Feng, L., Shi, L., Lu, Y. F., Wang, B., Tang, T., Fu, W. M., . . Zhang, J. F. (2018). LincROR Promotes Osteogenic Differentiation of Mesenchymal Stem Cells by Functioning as a Competing Endogenous RNA for miR-138 and miR-145. Mol Ther Nucleic Acids, 11, 345-353. doi:10.1016/j.omtn.2018.03.004

31. Flynn, R. A., \& Chang, H. Y. (2014). Long noncoding RNAs in cell-fate programming and reprogramming. Cell Stem Cell, 14(6), 752-761. doi:10.1016/j.stem.2014.05.014

32. Goode, D. K., Obier, N., Vijayabaskar, M. S., Lie, A. L. M., Lilly, A. J., Hannah, R., . . . Bonifer, C. (2016). Dynamic Gene Regulatory Networks Drive Hematopoietic Specification and Differentiation. Dev Cell, 36(5), 572-587. doi:10.1016/j.devcel.2016.01.024

33. Grote, P., \& Herrmann, B. G. (2015). Long noncoding RNAs in organogenesis: making the difference. Trends Genet, 31(6), 329-335. doi:10.1016/j.tig.2015.02.002

34. Guttman, M., Amit, I., Garber, M., French, C., Lin, M. F., Feldser, D., . . Lander, E. S. (2009). Chromatin signature reveals over a thousand highly conserved large non-coding RNAs in mammals. Nature, 458(7235), 223-227. doi:10.1038/nature07672

35. Guttman, M., Donaghey, J., Carey, B. W., Garber, M., Grenier, J. K., Munson, G., . . . Lander, E. S. (2011). lincRNAs act in the circuitry controlling pluripotency and differentiation. Nature, 477(7364), 295-300. doi:10.1038/nature10398

36. Hacisuleyman, E., Goff, L. A., Trapnell, C., Williams, A., Henao-Mejia, J., Sun, L., . . . Rinn, J. L. (2014). Topological organization of multichromosomal regions by the long 
intergenic noncoding RNA Firre. Nat Struct Mol Biol, 21(2), 198-206. doi: $10.1038 / \mathrm{nsmb} .2764$

37. Herriges, M. J., Swarr, D. T., Morley, M. P., Rathi, K. S., Peng, T., Stewart, K. M., \& Morrisey, E. E. (2014). Long noncoding RNAs are spatially correlated with transcription factors and regulate lung development. Genes Dev, 28(12), 1363-1379. doi:10.1101/gad.238782.114

38. Jacob, M. D., Audas, T. E., Uniacke, J., Trinkle-Mulcahy, L., \& Lee, S. (2013). Environmental cues induce a long noncoding RNA-dependent remodeling of the nucleolus. Mol Biol Cell, 24(18), 2943-2953. doi:10.1091/mbc.E13-04-0223

39. Jensen, L. J., Kuhn, M., Stark, M., Chaffron, S., Creevey, C., Muller, J., . . von Mering, C. (2009). STRING 8--a global view on proteins and their functional interactions in 630 organisms. Nucleic Acids Res, 37(Database issue), D412-416. doi:10.1093/nar/gkn760

40. Jin, C., Zheng, Y., Huang, Y., Liu, Y., Jia, L., \& Zhou, Y. (2017). Long non-coding RNA MIAT knockdown promotes osteogenic differentiation of human adipose-derived stem cells. Cell Biol Int, 41(1), 33-41. doi:10.1002/cbin.10697

41. Kataruka, S., Akhade, V. S., Kayyar, B., \& Rao, M. R. S. (2017). Mrhl Long Noncoding RNA Mediates Meiotic Commitment of Mouse Spermatogonial Cells by Regulating Sox 8 Expression. Mol Cell Biol, 37(14). doi:10.1128/mcb.00632-16

42. Klattenhoff, C. A., Scheuermann, J. C., Surface, L. E., Bradley, R. K., Fields, P. A., Steinhauser, M. L., . . Boyer, L. A. (2013). Braveheart, a long noncoding RNA required for cardiovascular lineage commitment. Cell, 152(3), 570-583. doi:10.1016/j.cell.2013.01.003

43. Kleaveland, B., Shi, C. Y., Stefano, J., \& Bartel, D. P. (2018). A Network of Noncoding Regulatory RNAs Acts in the Mammalian Brain. Cell, 174(2), 350-362.e317. doi:10.1016/j.cell.2018.05.022

44. Klein, D., Benchellal, M., Kleff, V., Jakob, H. G., \& Ergun, S. (2013). Hox genes are involved in vascular wall-resident multipotent stem cell differentiation into smooth muscle cells. Sci Rep, 3, 2178. doi:10.1038/srep02178

45. Komori, T. (2002). Runx2, a multifunctional transcription factor in skeletal development. J Cell Biochem, 87(1), 1-8. doi:10.1002/jcb.10276

46. Lin, N., Chang, K. Y., Li, Z., Gates, K., Rana, Z. A., Dang, J., . . Rana, T. M. (2014). An evolutionarily conserved long noncoding RNA TUNA controls pluripotency and neural lineage commitment. Mol Cell, 53(6), 1005-1019. doi:10.1016/j.molcel.2014.01.021

47. Lin, Y. J., Hsin, I. L., Sun, H. S., Lin, S., Lai, Y. L., Chen, H. Y., . . Wu, H. M. (2018). NTF3 Is a Novel Target Gene of the Transcription Factor POU3F2 and Is Required for Neuronal Differentiation. Mol Neurobiol, 55(11), 8403-8413. doi:10.1007/s12035-0180995-y

48. Loewer, S., Cabili, M. N., Guttman, M., Loh, Y. H., Thomas, K., Park, I. H., . . Rinn, J. L. (2010). Large intergenic non-coding RNA-RoR modulates reprogramming of human induced pluripotent stem cells. Nat Genet, 42(12), 1113-1117. doi:10.1038/ng.710

49. Lu, M. H., Tang, B., Zeng, S., Hu, C. J., Xie, R., Wu, Y. Y., . . . Yang, S. M. (2016). Long noncoding RNA BC032469, a novel competing endogenous RNA, upregulates hTERT expression by sponging miR-1207-5p and promotes proliferation in gastric cancer. Oncogene, 35(27), 3524-3534. doi:10.1038/onc.2015.413 
50. Marchese, F. P., Grossi, E., Marin-Bejar, O., Bharti, S. K., Raimondi, I., Gonzalez, J., . . Huarte, M. (2016). A Long Noncoding RNA Regulates Sister Chromatid Cohesion. Mol Cell, 63(3), 397-407. doi:10.1016/j.molcel.2016.06.031

51. Martin, G. R. (1981). Isolation of a pluripotent cell line from early mouse embryos cultured in medium conditioned by teratocarcinoma stem cells. Proc Natl Acad Sci US A, 78(12), 7634-7638. doi:10.1073/pnas.78.12.7634

52. Mathelier, A., Zhao, X., Zhang, A. W., Parcy, F., Worsley-Hunt, R., Arenillas, D. J., . . . Wasserman, W. W. (2014). JASPAR 2014: an extensively expanded and updated openaccess database of transcription factor binding profiles. Nucleic Acids Res, 42(Database issue), D142-147. doi:10.1093/nar/gkt997

53. Mercer, T. R., Dinger, M. E., \& Mattick, J. S. (2009). Long non-coding RNAs: insights into functions. Nat Rev Genet, 10(3), 155-159. doi:10.1038/nrg2521

54. Mercer, T. R., Qureshi, I. A., Gokhan, S., Dinger, M. E., Li, G., Mattick, J. S., \& Mehler, M. F. (2010). Long noncoding RNAs in neuronal-glial fate specification and oligodendrocyte lineage maturation. BMC Neurosci, 11, 14. doi:10.1186/1471-2202-1114

55. Mondal, T., Subhash, S., Vaid, R., Enroth, S., Uday, S., Reinius, B., . . . Kanduri, C. (2015). MEG3 long noncoding RNA regulates the TGF-beta pathway genes through formation of RNA-DNA triplex structures. Nat Commun, 6, 7743. doi: $10.1038 /$ ncomms 8743

56. Nishant, K. T., Ravishankar, H., \& Rao, M. R. (2004). Characterization of a mouse recombination hot spot locus encoding a novel non-protein-coding RNA. Mol Cell Biol, 24(12), 5620-5634. doi:10.1128/mcb.24.12.5620-5634.2004

57. Niwa, H. (2018). The principles that govern transcription factor network functions in stem cells. Development, 145(6). doi:10.1242/dev.157420

58. Ohhata, T., Hoki, Y., Sasaki, H., \& Sado, T. (2008). Crucial role of antisense transcription across the Xist promoter in Tsix-mediated Xist chromatin modification. Development, 135(2), 227-235. doi:10.1242/dev.008490

59. Pandey, R. R., Mondal, T., Mohammad, F., Enroth, S., Redrup, L., Komorowski, J., .. . Kanduri, C. (2008). Kcnq1ot1 antisense noncoding RNA mediates lineage-specific transcriptional silencing through chromatin-level regulation. Mol Cell, 32(2), 232-246. doi:10.1016/j.molcel.2008.08.022

60. Perry, R. B., \& Ulitsky, I. (2016). The functions of long noncoding RNAs in development and stem cells. Development, 143(21), 3882-3894. doi:10.1242/dev.140962

61. Pijnappel, W., P.A. Baltissen, M., \& Timmers, H. T. M. (2013). Protocol for lentiviral knock down in mouse ES cells.

62. Postepska-Igielska, A., Giwojna, A., Gasri-Plotnitsky, L., Schmitt, N., Dold, A., Ginsberg, D., \& Grummt, I. (2015). LncRNA Khps1 Regulates Expression of the Protooncogene SPHK1 via Triplex-Mediated Changes in Chromatin Structure. Mol Cell, 60(4), 626-636. doi:10.1016/j.molcel.2015.10.001

63. Price, F. D., Yin, H., Jones, A., van Ijcken, W., Grosveld, F., \& Rudnicki, M. A. (2013). Canonical Wnt signaling induces a primitive endoderm metastable state in mouse embryonic stem cells. Stem Cells, 31(4), 752-764. doi:10.1002/stem.1321

64. Quinlan, A. R., \& Hall, I. M. (2010). BEDTools: a flexible suite of utilities for comparing genomic features. Bioinformatics, 26(6), 841-842. doi:10.1093/bioinformatics/btq033 
65. Rinn, J. L., Kertesz, M., Wang, J. K., Squazzo, S. L., Xu, X., Brugmann, S. A., . . . Chang, H. Y. (2007). Functional demarcation of active and silent chromatin domains in human HOX loci by noncoding RNAs. Cell, 129(7), 1311-1323. doi:10.1016/j.cell.2007.05.022

66. Ripoche, M. A., Kress, C., Poirier, F., \& Dandolo, L. (1997). Deletion of the H19 transcription unit reveals the existence of a putative imprinting control element. Genes Dev, 11(12), 1596-1604. doi:10.1101/gad.11.12.1596

67. Salguero-Aranda, C., Tapia-Limonchi, R., Cahuana, G. M., Hitos, A. B., Diaz, I., Hmadcha, A., . . Bedoya, F. J. (2016). Differentiation of Mouse Embryonic Stem Cells toward Functional Pancreatic beta-Cell Surrogates through Epigenetic Regulation of Pdx1 by Nitric Oxide. Cell Transplant, 25(10), 1879-1892. doi:10.3727/096368916x691178

68. Sarangdhar, M. A., Chaubey, D., Srikakulam, N., \& Pillai, B. (2018). Parentally inherited long non-coding RNA Cyrano is involved in zebrafish neurodevelopment. Nucleic Acids Res, 46(18), 9726-9735. doi:10.1093/nar/gky628

69. Sarropoulos, I., Marin, R., Cardoso-Moreira, M., \& Kaessmann, H. (2019). Developmental dynamics of lncRNAs across mammalian organs and species. Nature. doi:10.1038/s41586-019-1341-x

70. Shannon, P., Markiel, A., Ozier, O., Baliga, N. S., Wang, J. T., Ramage, D., . . Ideker, T. (2003). Cytoscape: a software environment for integrated models of biomolecular interaction networks. Genome Res, 13(11), 2498-2504. doi:10.1101/gr.1239303

71. Sheik Mohamed, J., Gaughwin, P. M., Lim, B., Robson, P., \& Lipovich, L. (2010). Conserved long noncoding RNAs transcriptionally regulated by Oct4 and Nanog modulate pluripotency in mouse embryonic stem cells. Rna, 16(2), 324-337. doi:10.1261/rna.1441510

72. Shevtsov, S. P., \& Dundr, M. (2011). Nucleation of nuclear bodies by RNA. Nat Cell Biol, 13(2), 167-173. doi:10.1038/ncb2157

73. Shiba, Y., Fernandes, S., Zhu, W. Z., Filice, D., Muskheli, V., Kim, J., . . Laflamme, M. A. (2012). Human ES-cell-derived cardiomyocytes electrically couple and suppress arrhythmias in injured hearts. Nature, 489(7415), 322-325. doi:10.1038/nature11317

74. Shroff, G., \& Gupta, R. (2015). Human embryonic stem cells in the treatment of patients with spinal cord injury. Ann Neurosci, 22(4), 208-216. doi:10.5214/ans.0972.7531.220404

75. Sleutels, F., Zwart, R., \& Barlow, D. P. (2002). The non-coding Air RNA is required for silencing autosomal imprinted genes. Nature, 415(6873), 810-813. doi:10.1038/415810a

76. Smith, K. N., Starmer, J., Miller, S. C., Sethupathy, P., \& Magnuson, T. (2017). Long Noncoding RNA Moderates MicroRNA Activity to Maintain Self-Renewal in Embryonic Stem Cells. Stem Cell Reports, 9(1), 108-121. doi:10.1016/j.stemcr.2017.05.005

77. Sokol, S. Y. (2011). Maintaining embryonic stem cell pluripotency with Wnt signaling. Development, 138(20), 4341-4350. doi:10.1242/dev.066209

78. Souquere, S., Beauclair, G., Harper, F., Fox, A., \& Pierron, G. (2010). Highly ordered spatial organization of the structural long noncoding NEAT1 RNAs within paraspeckle nuclear bodies. Mol Biol Cell, 21(22), 4020-4027. doi:10.1091/mbc.E10-08-0690

79. Sun, Q., Hao, Q., \& Prasanth, K. V. (2018). Nuclear Long Noncoding RNAs: Key Regulators of Gene Expression. Trends Genet, 34(2), 142-157. doi:10.1016/j.tig.2017.11.005 
80. Sun, Z., Zhu, M., Lv, P., Cheng, L., Wang, Q., Tian, P., . . . Wen, B. (2018). The Long Noncoding RNA Lncenc1 Maintains Naive States of Mouse ESCs by Promoting the Glycolysis Pathway. Stem Cell Reports, 11(3), 741-755. doi:10.1016/j.stemcr.2018.08.001

81. Thomas, P. D., Campbell, M. J., Kejariwal, A., Mi, H., Karlak, B., Daverman, R., . . . Narechania, A. (2003). PANTHER: a library of protein families and subfamilies indexed by function. Genome Res, 13(9), 2129-2141. doi:10.1101/gr.772403

82. Trapnell, C., Roberts, A., Goff, L., Pertea, G., Kim, D., Kelley, D. R., . . . Pachter, L. (2012). Differential gene and transcript expression analysis of RNA-seq experiments with TopHat and Cufflinks. Nat Protoc, 7(3), 562-578. doi:10.1038/nprot.2012.016

83. Tsui, D., Vessey, J. P., Tomita, H., Kaplan, D. R., \& Miller, F. D. (2013). FoxP2 regulates neurogenesis during embryonic cortical development. J Neurosci, 33(1), 244258. doi:10.1523/jneurosci.1665-12.2013

84. Tu, J., Tian, G., Cheung, H. H., Wei, W., \& Lee, T. L. (2018). Gas5 is an essential lncRNA regulator for self-renewal and pluripotency of mouse embryonic stem cells and induced pluripotent stem cells. Stem Cell Res Ther, 9(1), 71. doi:10.1186/s13287-0180813-5

85. Ulitsky, I., Shkumatava, A., Jan, C. H., Sive, H., \& Bartel, D. P. (2011). Conserved function of lincRNAs in vertebrate embryonic development despite rapid sequence evolution. Cell, 147(7), 1537-1550. doi:10.1016/j.cell.2011.11.055

86. Urban, S., Kobi, D., Ennen, M., Langer, D., Le Gras, S., Ye, T., \& Davidson, I. (2015). A Brn2-Zic1 axis specifies the neuronal fate of retinoic-acid-treated embryonic stem cells. $J$ Cell Sci, 128(13), 2303-2318. doi:10.1242/jcs.168849

87. Wang, S., Ke, H., Zhang, H., Ma, Y., Ao, L., Zou, L., . . . Jiao, B. (2018). LncRNA MIR100HG promotes cell proliferation in triple-negative breast cancer through triplex formation with p27 loci. Cell Death Dis, 9(8), 805. doi:10.1038/s41419-018-0869-2

88. Wang, Y., Xu, Z., Jiang, J., Xu, C., Kang, J., Xiao, L., . . Liu, H. (2013). Endogenous miRNA sponge lincRNA-RoR regulates Oct4, Nanog, and Sox2 in human embryonic stem cell self-renewal. Dev Cell, 25(1), 69-80. doi:10.1016/j.devcel.2013.03.002

89. Warde-Farley, D., Donaldson, S. L., Comes, O., Zuberi, K., Badrawi, R., Chao, P., ... Morris, Q. (2010). The GeneMANIA prediction server: biological network integration for gene prioritization and predicting gene function. Nucleic Acids Res, 38(Web Server issue), W214-220. doi:10.1093/nar/gkq537

90. Yo, K., \& Runger, T. M. (2018). The long non-coding RNA FLJ46906 binds to the transcription factors NF-kappaB and AP-1 and regulates expression of aging-associated genes. Aging (Albany NY), 10(8), 2037-2050. doi:10.18632/aging.101528

91. Zhao, J., Sun, B. K., Erwin, J. A., Song, J. J., \& Lee, J. T. (2008). Polycomb proteins targeted by a short repeat RNA to the mouse X chromosome. Science, 322(5902), 750756. doi:10.1126/science. 1163045

92. Zhou, S., Flamier, A., Abdouh, M., Tetreault, N., Barabino, A., Wadhwa, S., \& Bernier, G. (2015). Differentiation of human embryonic stem cells into cone photoreceptors through simultaneous inhibition of BMP, TGFbeta and Wnt signaling. Development, 142(19), 3294-3306. doi:10.1242/dev.125385 
A

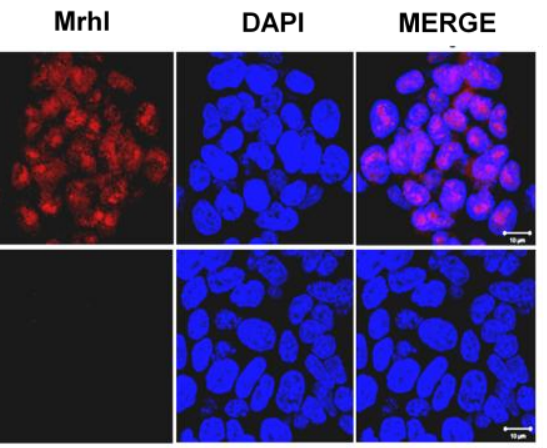

(+) RNAse

(-) RNAse

D
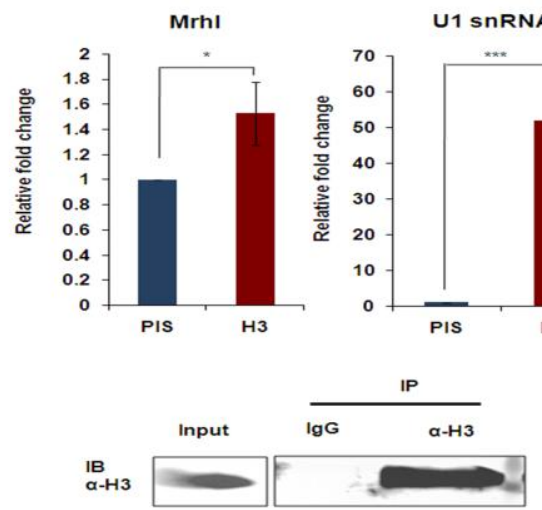

B
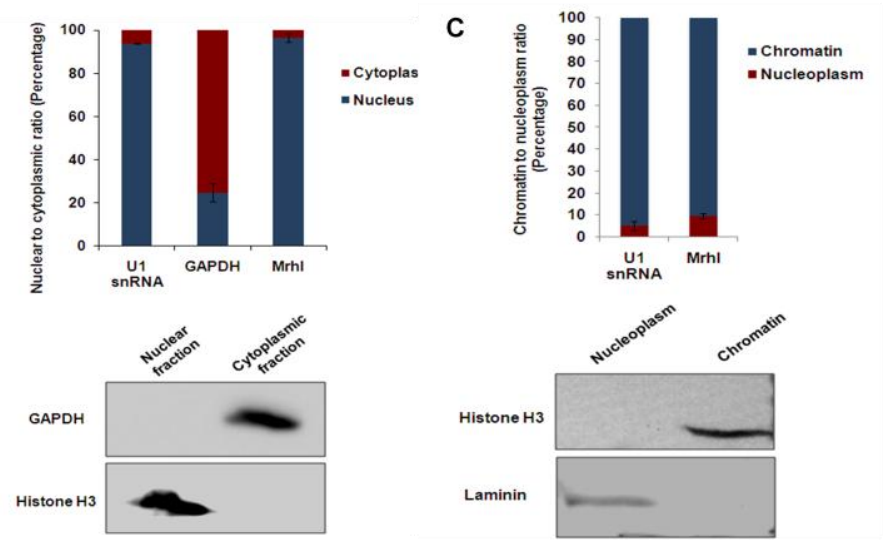

$\mathrm{E}$

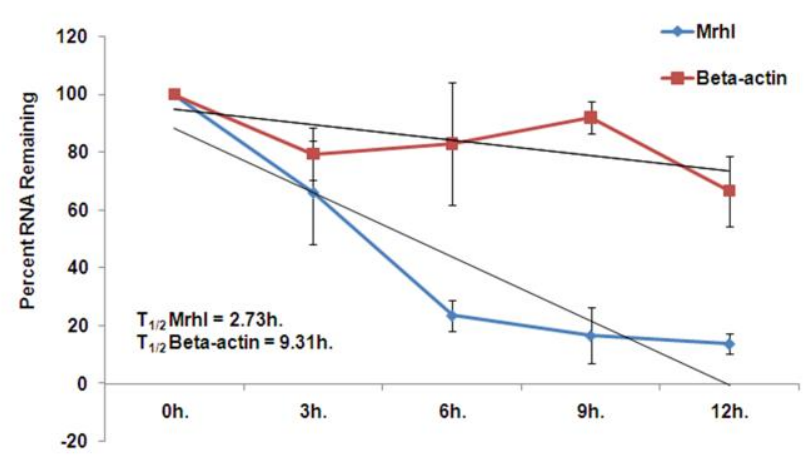

Figure 1: Mrhl is a nuclear-localized, chromatin bound moderately stable IncRNA in mESCs. (A) RNA FISH shows

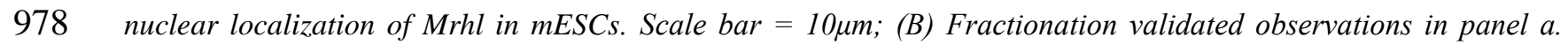

979 Western blot shows purity of fractions; (C) Chromatin and nucleoplasm fractions of nuclei show localization of

980 Mrhl to chromatin. Western blot shows purity of fractions; (D) H3 ChIP and qPCR reveal Mrhl is bound with the

981 chromatin in mESCs; (E) Actinomycin D half-life assay for Mrhl in mESCs. Error bars indicate standard deviation

982 from three independent experiments. ${ }^{*}<<0.05,{ }^{*} p<0.01$, ***p $<0.001$, student's t-test; Scale bar $=10 \mu m$. 
A
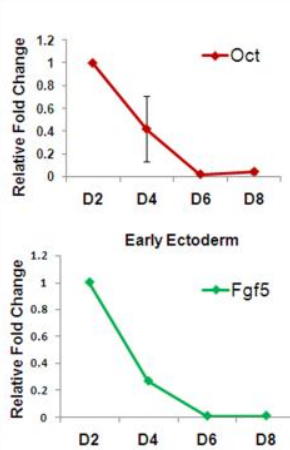

Late Mesoderm

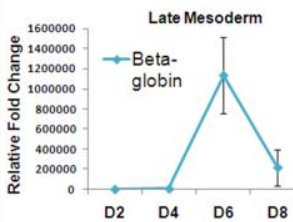

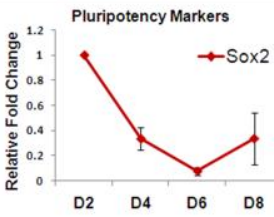
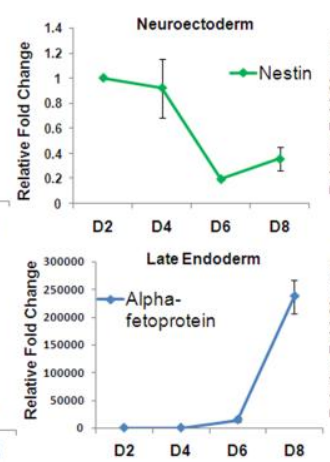
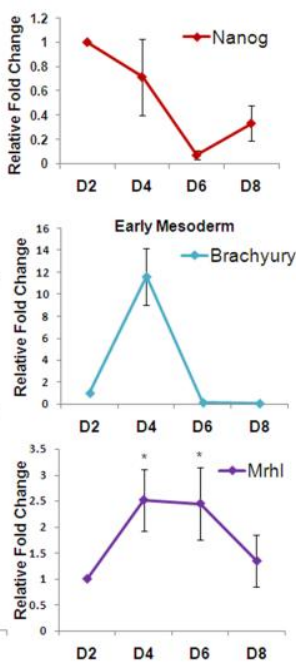

B

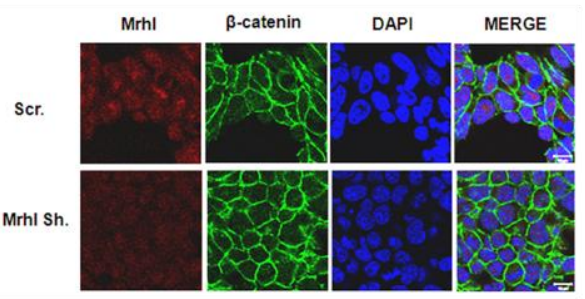

C

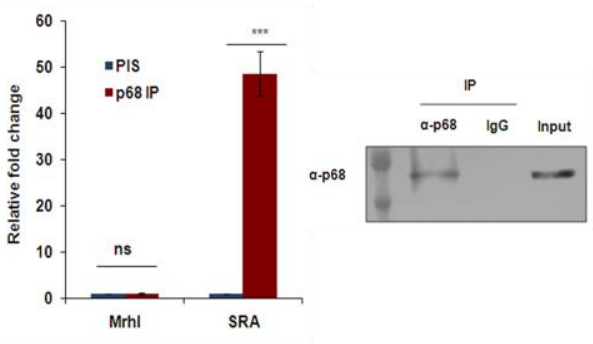

D

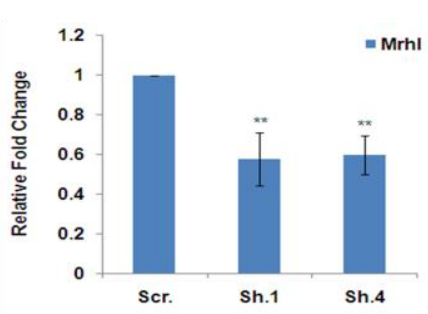

$\mathbf{F}$
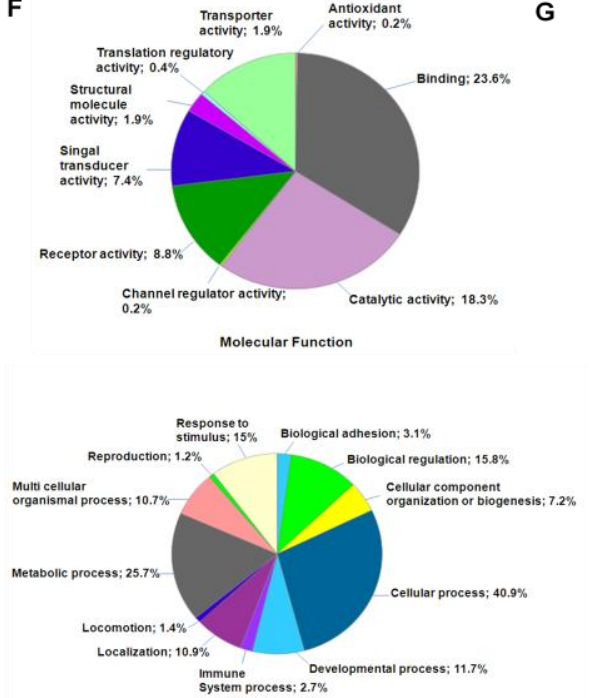

G
E
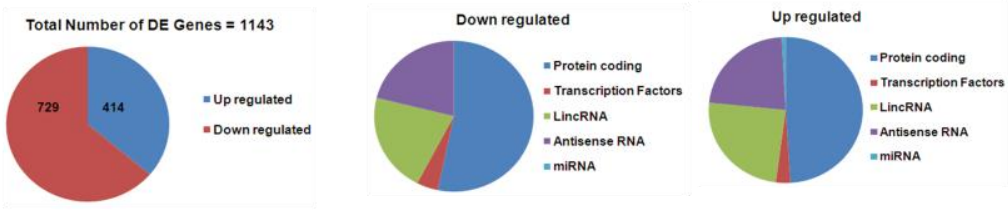

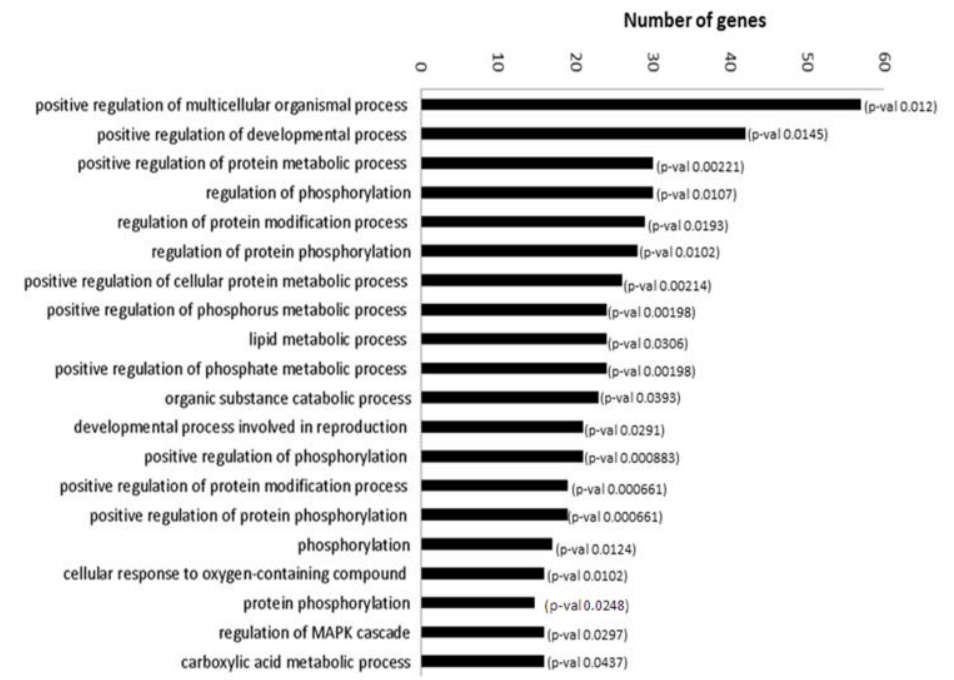

986 Figure 2: Analysis of role of Mrhl in mESCs through differentiation assay, knockdown and transcriptome analysis.

987 (A) Mrhl shows differential expression during embryoid body differentiation of mESCs; (B,C) Mrhl does not

988 function through the WNT/p68 cascade unlike in spermatogonial progenitors; (D) Knockdown efficiency of Mrhl in mESCs through two independent constructs i.e. sh.1 and sh.4 as compared to scrambled (scr.); (E) Representation

990 of DEG classification; $(F)$ Gene ontology analysis of DEG; $(G)$ GO enrichment analysis of DEG. Error bars

991 indicate standard deviation from three independent experiments. ${ }^{*} p<0.05,{ }^{*} p<0.01,{ }^{* * *} p<0.001$, student's $t$-test;

992 Scale bar $=10 \mu \mathrm{m}$. 
A

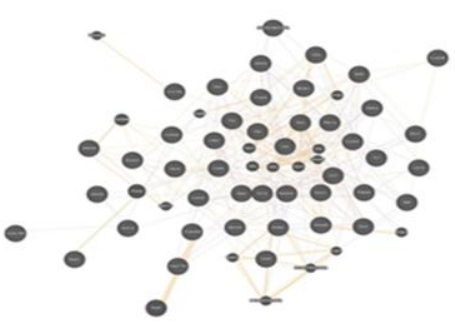

Cluster 1: No functional enrichment

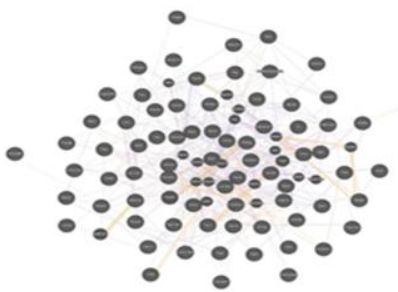

Cluster 4: Ion Channel Activity
- gated channel activity

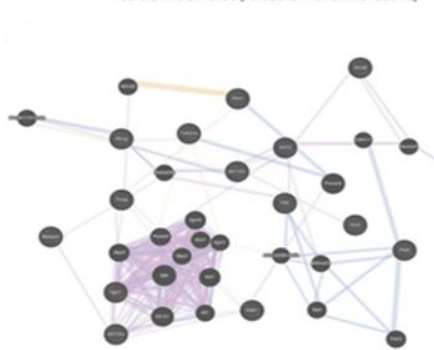

Cluster 7 : Immune System

intracellular region of host

cellutarlesponse to interferon-beta

hostintracellutarm part

hostcell cytoplasm

response to interferon-beta
host cell part
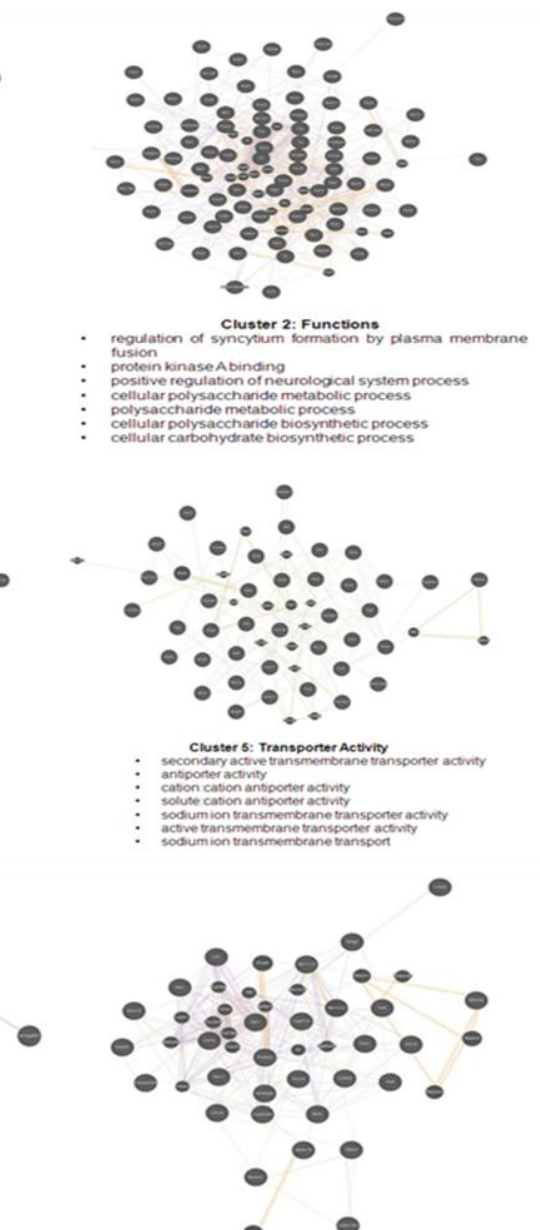

Cluster 8: Xenobiotic Processes cellular response to xenobiotic stimulus xenobiotic metabolic process
response to xenobiotic stimulus

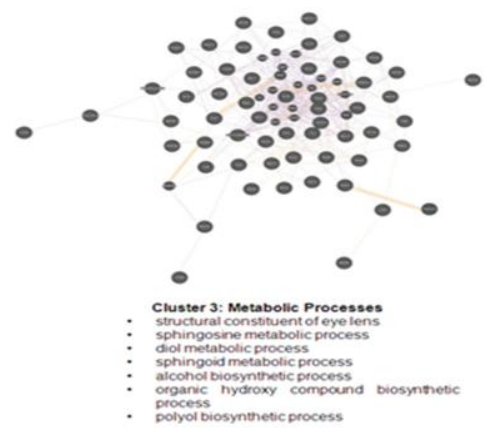

B

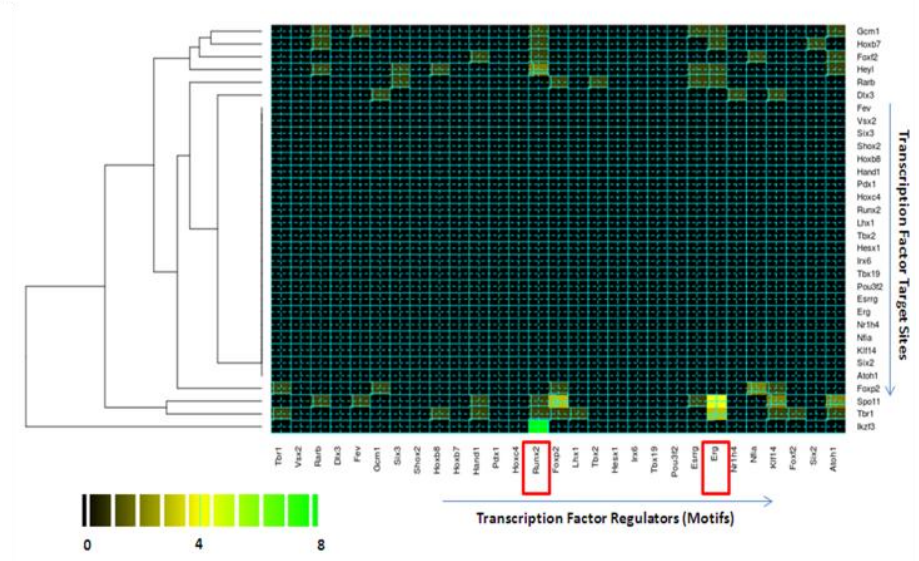

C

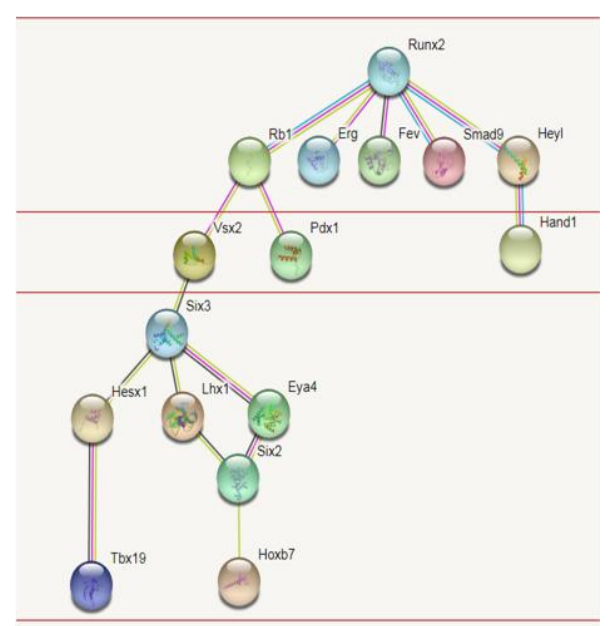

994

Figure 3: Gene co-expression and TF network analyses. (A) Gene co-expression modules and their corresponding

996 functional enrichments; (B) Heat map visualization of TF matrix; $(C)$ TF hierarchy as visualized in STRING. 
A
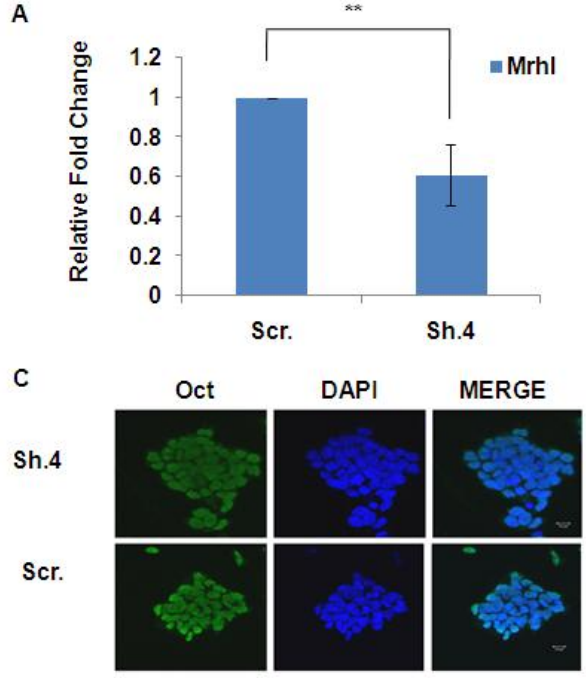

B

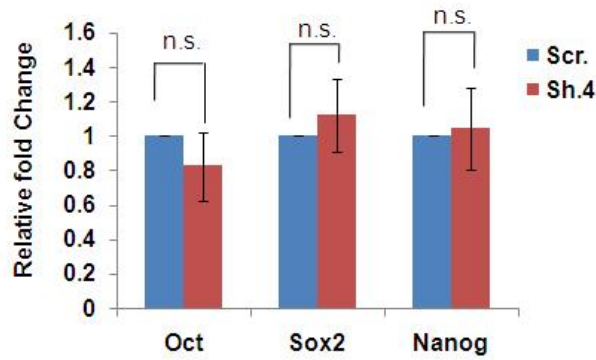

D
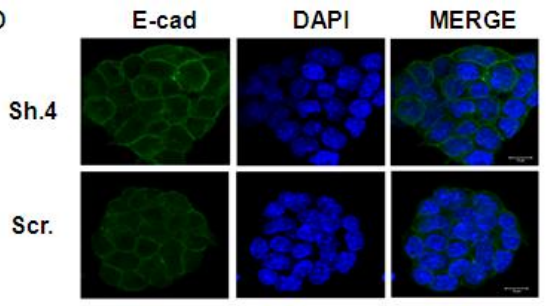

$\mathbf{F}$

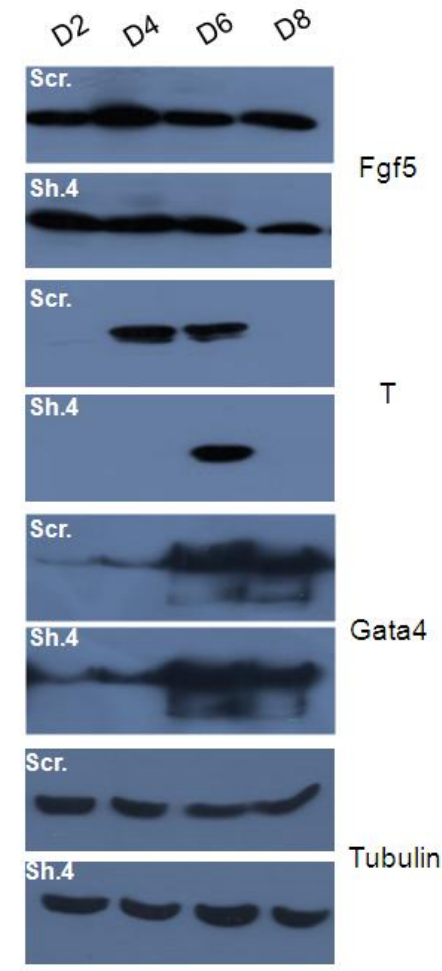

E
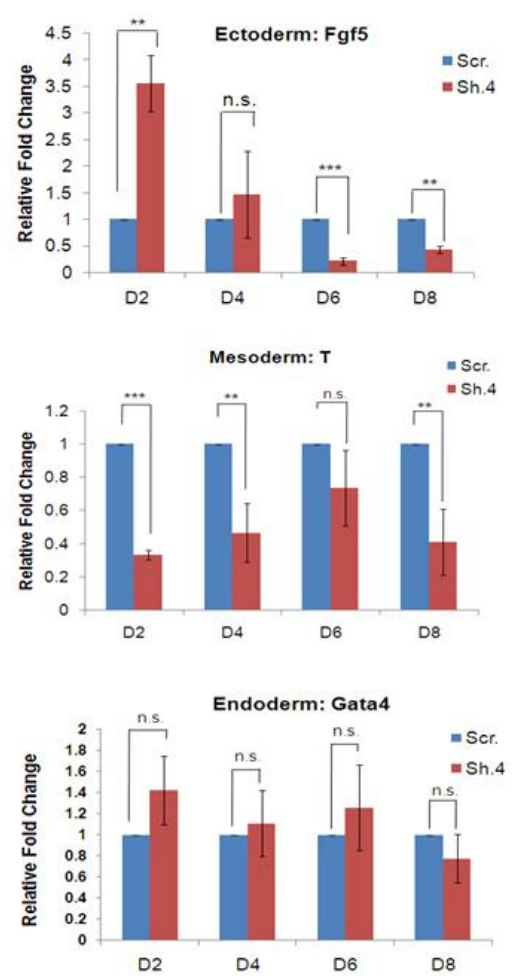

Figure 4: Stable knockdown of Mrhl in mESCs causes no change in pluripotency status but aberrance in lineage specification. (A) Knockdown efficiency in puromycin selected stable knockdown cells; (B) qRT-PCR for status; (E) qRT-PCR for lineage-specific markers upon EB differentiation of stable knockdown cells as compared to scrambled control; $(F)$ Western blots to confirm altered expression of lineage markers. Error bars indicate standard deviation from three independent experiments. ${ }^{*} p<0.05,{ }^{*} p<0.01,{ }^{* * *} p<0.001$, student's $t$-test; Panel $E$ is

1004 representative data from one of three independent experiments, each carried out in biological triplicates; Scale bar $1005=10 \mu \mathrm{m}$. 
A

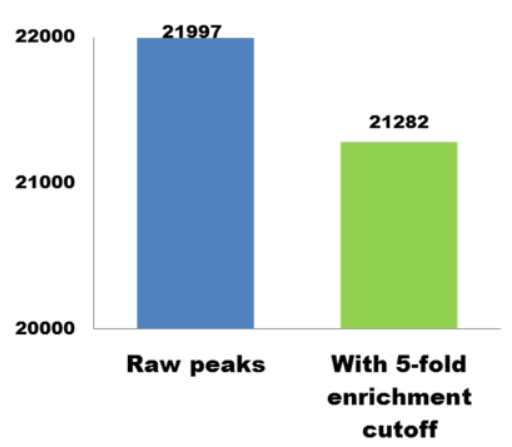

C

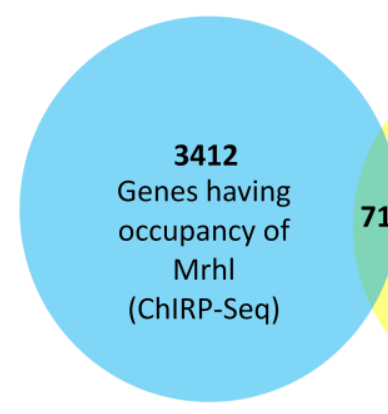

B

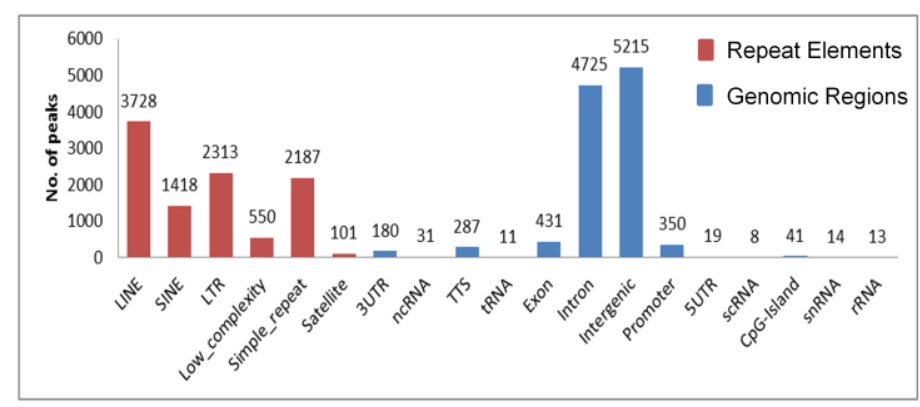

D
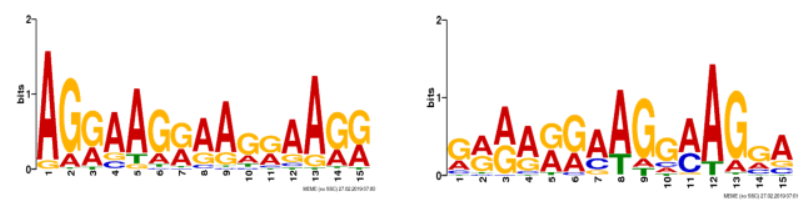

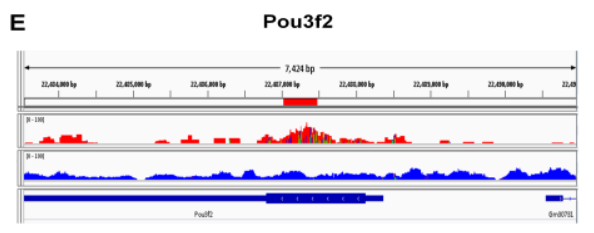

RNA-Seq DEG

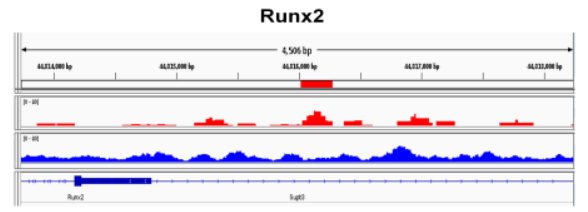

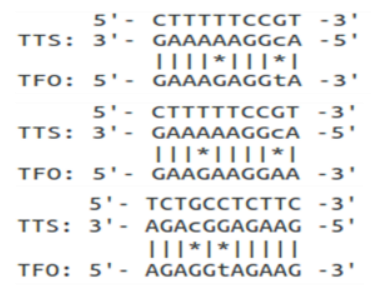

(1)

1019

1020 Figure 5: ChiRP-Seq analysis for Mrhl in mESCs. (A) Number of peaks obtained before and after cutoff; (B)

1021 Annotation of peaks; (C) Overlap of ChIRP-Seq and RNA-Seq datasets; (D) Motif analysis for genome occupancy 1022 for Mrhl on target genes; $(E)$ Triplex formation prediction at select loci involved in development and differentiation 1023 functions. 